\title{
Alzheimer's Disease: Biomarkers in the Genome, Blood, and Cerebrospinal Fluid
}

\author{
Rose Ann Huynh* and Chandra Mohan* \\ Department of Biomedical Engineering, University of Houston, Houston, TX, USA
}

Alzheimer's disease (AD) is a progressive neurodegenerative disorder that slowly destroys memory and thinking skills, resulting in behavioral changes. It is estimated that nearly 36 million are affected globally with numbers reaching 115 million by 2050. AD can only be

OPEN ACCESS

Edited by:

Marc Dhenain,

Centre national de la recherche scientifique (CNRS), France

Reviewed by:

Nelly Joseph-Mathurin, Washington University in St. Louis, USA

Julien Chapuis,

University of Lille, France

*Correspondence:

Rose Ann Huynh roseannhuynh@gmail.com; Chandra Mohan

cmohan@central.uh.edu

Specialty section:

This article was submitted to

Neurodegeneration,

a section of the journal

Frontiers in Neurology

Received: 06 October 2016

Accepted: 01 March 2017

Published: 20 March 2017

Citation:

Huynh RA and Mohan C (2017)

Alzheimer's Disease: Biomarkers in

the Genome, Blood, and

Cerebrospinal Fluid.

Front. Neurol. 8:102.

doi: 10.3389/fneur.2017.00102 definitively diagnosed at autopsy since its manifestations of senile plaques and neurofibrillary tangles throughout the brain cannot yet be fully captured with current imaging technologies. Current AD therapeutics have also been suboptimal. Besides identifying markers that distinguish $A D$ from controls, there has been a recent drive to identify better biomarkers that can predict the rates of cognitive decline and neocortical amyloid burden in those who exhibit preclinical, prodromal, or clinical AD. This review covers biomarkers of three main types: genes, cerebrospinal fluid-derived, and blood-derived biomarkers. Looking ahead, cutting-edge OMICs technologies, including proteomics and metabolomics, ought to be fully tapped in order to mine even better biomarkers for AD that are more predictive.

Keywords: Alzheimer's disease, early detection, genetic biomarkers, neurochemical biomarkers, blood-derived biomarkers, longitudinal studies

Abbreviations: $\mathrm{AAO}$, age at symptom onset; $\mathrm{A} \beta_{42}$, amyloid-beta1-42 peptide; $\mathrm{ACs}$, acylcarnitines; $\mathrm{AD}$, Alzheimer's disease; $\mathrm{ADAD}$, autosomal-dominant for $\mathrm{AD}$; $\mathrm{A} 1 \mathrm{AT}$, alpha- 1 antitrypsin; $\mathrm{aMCI}$, amnestic mild cognitive impairment; $\mathrm{A} \beta \mathrm{PP}$, amyloid- $\beta$ precursor protein; $\mathrm{APOE} / \mathrm{ApoE}$, apolipoprotein $\mathrm{E}$; $\mathrm{BACE} 1, \beta$-site amyloid precursor protein cleaving enzyme; $\mathrm{BBB}$, blood-brain barrier; BIN1, bridging integrator 1; BDNF, brain-derived neurotrophic factor; CDR-SB, clinical dementia rating sum of boxes;

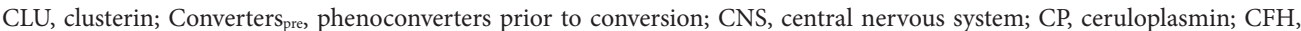
complement factor H; CR1, complement receptor 1; CSF, cerebrospinal fluid; DIAN, dominantly inherited Alzheimer network; DLB, dementia with Lewy bodies; EAO, estimated age at symptom onset; EOAD, early onset Alzheimer's disease; EYOs, estimated number of years to symptom onset; FGG, fibrinogen $\gamma$-chain; FTD, frontotemporal dementia. GRS; Genetic Risk Score; GWAS, genome-wide association studies; HC, healthy control; HuGENet, human genome epidemiology network; LOAD, late onset Alzheimer's disease; naMCI, non-amnestic mild cognitive impairment; MMSE, mini-mental state examination; MCs, mutation carriers; NAND, non-AD neurodegenerative dementias; NFTs, neurofibrillary tangles; NGRN, neurogranin; NSE, neuron-specific enolase; NGS, next-generation sequencing; NCs, non-carriers; OR, odds ratio; PICALM, phosphatidylinositol clathrin assembly lymphoid-myeloid; PAGE, polyacrylamide gel electrophoresis; $p$-tau, phosphorylated tau; PAI, plasminogen activator inhibitor; PAM, predictive analysis of microarrays; PEDF, pigment epithelium-derived factor; PET, positive emission tomography; PC, phosphatidylcholine; PDD, Parkinson's disease dementia; PPV/NPV, positive predictive value/negative predictive value; PSEN, presenilin; SAP, serum amyloid P-component precursor; SUVR, standardized uptake value ratio; SVM, support vector machine; TREM2, triggering receptor expressed on myeloid cells 2; T-Tau, total tau; VAD, vascular dementia; VCAM, vascular adhesion molecule; VILIP, visinin-like-protein; 2-DGE, 2-D gel electrophoresis. 


\section{INTRODUCTION}

Alzheimer's disease (AD) is a progressive neurodegenerative disorder that slowly destroys memory and thinking skills, resulting in behavioral changes. This places an emotional toll on the patients' caretakers, while placing a financial burden of approximately $\$ 214$ billion in 2014 alone on the American society (1). The number of those affected is expected to reach 115 million worldwide by 2050. Thus, there is an ever-growing need to find biomarkers for the early diagnosis of $\mathrm{AD}$ as well as to predict disease progression. $\mathrm{AD}$ is defined by the presence of senile plaques and neurofibrillary tangles (NFTs) throughout the brain resulting in its shrinkage. Definitive $\mathrm{AD}$ pathology can only be determined at autopsy since these neurologic manifestations are not readily perceptible using current diagnostic technologies, making early diagnosis difficult and inaccurate $(1,2)$. Current scientific evidence suggests that in preclinical Alzheimer's, brain changes caused by the disease may begin years before symptoms of mild cognitive impairment (MCI) set in Ref. (3). Also, current therapeutic approaches have been largely inadequate toward addressing the earliest clinical symptoms of $\mathrm{AD}$, where neurological damage is irreversible (4). Thus, comprehensive research is being performed to identify better biomarkers for the early detection of $\mathrm{AD}$ with the hope that an effective therapeutic window will emerge.

As Alzheimer's research has progressed, two clinically accepted validated biomarkers, amyloid- $\beta(\mathrm{A} \beta)$ accumulation in cerebrospinal fluid (CSF) and Pittsburgh compound B positron emission tomography (PiB-PET) measurements, have changed the primary focus of biomarker research from differentiation between cognitively normal healthy controls $(\mathrm{HC})$ and $\mathrm{AD}$, to the ability of potential biomarkers to predict the rates of cognitive decline in those who exhibit preclinical, prodromal, or clinical $\mathrm{AD}(3,5-8)$. Previous review articles have shed light on potential biomarkers meeting some of these criteria including imaging and animal studies (9-14). In contrast to those reviews, the present article will focus on updating our current understanding of $\mathrm{AD}$ biomarkers harnessed from the genome, the CSF, or the blood, since there have been rapid developments in this arena; moreover, the laboratory assays for these biomarkers are relatively inexpensive (compared to neuroimaging modalities). At the close of this review, we will also discuss longitudinal studies utilizing these biomarkers, individually and in combination, to better evaluate which of these may be clinically useful as long-term markers of $\mathrm{AD}$ progression.

\section{GENETIC BIOMARKERS}

Several researchers have investigated the genetic makeup of those afflicted with Alzheimer's compared to neurologically healthy individuals. Amyloid- $\beta$ precursor protein $(A \beta P P)$, presenilin 1 (PSEN1), and presenilin 2 (PSEN2) genes have been strongly implicated in early onset Alzheimer's disease (EOAD), particularly familial EOAD, which comprise less than $5 \%$ of Alzheimer's cases (15). In contrast, late onset Alzheimer's disease (LOAD) has been associated with other genes including apolipoprotein E-ع4 (APOE ع4), bridging integrator 1 (BIN1) region, clusterin $(C L U)$, phosphatidylinositol clathrin assembly lymphoid-myeloid
(PICALM), and complement receptor 1 , mostly identified through genome-wide association studies (GWAS) (http://www.alzgene. org/). Among these most highly associated genes for LOAD, the $A P O E \& 4$ allele emerges as the most promising candidate. This relative rank of gene association to $\mathrm{AD}$ is based on the human genome epidemiology network interim criteria for the cumulative assessment of genetic associations, which takes into account the sample size, heterogeneity across studies, and protection from bias within these studies.

Genetic tests are available for both $A P O E \& 4$ and the rare genes associated with EOAD. Traditionally, screening for $\mathrm{AD}$ associated genes via targeted sequencing methods, whether through Sanger or next-generation sequencing (NGS), was more commonly used than whole-exome sequencing due to lower costs and faster analysis (16). However, as the cost and running time of whole-exome sequencing has decreased, particularly through refined NGS methods, it has become a more widely used tool for genetic screening $(17,18)$. However, routine clinical testing for early detection is not currently recommended for most EOAD individuals since there is currently no effective treatment or prevention for $\mathrm{AD}$. Moreover, the identification of a mutation is not a certain predictor of disease or onset age, given that these mutations can vary in terms of penetrance and gene expression (19). However, an increasing number of studies report the benefits of disclosing Alzheimer's diagnosis early since it allows the patient to plan for their future with better access to good medical care and support services, as reviewed elsewhere (20). In fact, PSEN1 and PSEN2 testing is now recommended for individuals with early onset dementia who have at least one affected family member. PSEN2 testing is even further recommended for those individuals who also present with delusions or hallucinations (21). Likewise, $A \beta P P$ testing is now recommended for individuals with early onset dementia who have at least one affected family member and in whom no PSEN1 mutation has been identified (21).

\section{APOE $\varepsilon 4$ ALLELE}

Among the many genes examined, the APOE $\varepsilon 4$ allele emerges as the strongest genetic risk factor for $\mathrm{AD}(22)$. ApoE regulates lipid homeostasis by mediating lipid transport from one tissue or cell type to another. In the central nervous system (CNS), ApoE is produced mainly by astrocytes where they transport cholesterol to neurons via ApoE receptors (23). In humans, APOE polymorphism is represented by three different alleles: $\varepsilon 2$, $\varepsilon 3$, and $\varepsilon 4$, which generally occur at frequencies of $8.4,77.9$, and $13.7 \%$, respectively, in Caucasian populations $(24,25)$. However, in those afflicted with $\mathrm{AD}$, the frequencies are altered to 3.9, 59.4 , and $36.7 \%$ for the $\varepsilon 2, \varepsilon 3$, and $\varepsilon 4$ alleles, respectively. These frequencies vary based on ethnic groups; whereas the Japanese population exhibits the highest, the Hispanic population exhibits the lowest frequency differences of the homozygous APOE $\varepsilon 4$ allele in AD patients versus healthy controls $(24,25)$. This difference in $\mathrm{AD}$ frequencies between ethnic groups is also reflected in their respective odds ratios (ORs) for AD: whereas the Japanese population exhibits the highest OR (33.1), the Hispanic population exhibits the lowest (2.2) OR for the APOE $\varepsilon 4$ homozygous genotype (Table 1). 
TABLE 1 | Comparison of APOE 84 allele as a marker for AD in various studies.

\begin{tabular}{|c|c|c|c|c|c|c|c|}
\hline Reference & $\begin{array}{l}\text { Disease comparison } \\
\text { (ethnic group) }^{\mathrm{a}}\end{array}$ & $\begin{array}{l}\text { No. of cases } \\
\text { (AD/non-AD) }\end{array}$ & $\begin{array}{l}\text { APOE \&4 allele } \\
\text { carrier type }\end{array}$ & $\begin{array}{l}\text { Specificity } \\
\text { (95\% Cl) }\end{array}$ & $\begin{array}{l}\text { Sensitivity } \\
\text { (95\% CI) }\end{array}$ & PPV/NPV & $\begin{array}{c}\text { OR } \\
(95 \% \mathrm{Cl})\end{array}$ \\
\hline \multirow[t]{4}{*}{ Farrer et al. (24) } & AD versus $\mathrm{HC}$ (Caucasian) & $(193 / 6,262)$ & Homozygous & $\mathrm{N} / \mathrm{A}$ & N/A & $\mathrm{N} / \mathrm{A}$ & $12.5(8.8-17.7)$ \\
\hline & $A D$ versus $H C$ (African American) & $(34 / 240)$ & Homozygous & N/A & N/A & N/A & $5.7(2.3-14.1)$ \\
\hline & AD versus $\mathrm{HC}$ (Hispanics) & $(12 / 267)$ & Homozygous & $\mathrm{N} / \mathrm{A}$ & N/A & N/A & $2.2(0.7-6.7)$ \\
\hline & AD versus HC (Japanese) & $(45 / 1,977)$ & Homozygous & $\mathrm{N} / \mathrm{A}$ & N/A & $\mathrm{N} / \mathrm{A}$ & $33.1(13.6-80.5)$ \\
\hline \multirow[t]{2}{*}{ Saunders et al. (26) } & $A D$ versus $H C$ & $(46 / 10)$ & Heterozygous & 1 & 0.75 & $1.0 / 0.42$ & $\mathrm{~N} / \mathrm{A}$ \\
\hline & $A D$ versus $H C$ & $(11 / 10)$ & Homozygous & 1 & 0.19 & $1 / 0.18$ & N/A \\
\hline \multirow{2}{*}{$\begin{array}{l}\text { Elias-Sonnenschein } \\
\text { et al. (27) }\end{array}$} & $A D$ versus $M C l$ & $(35 / 35)$ & Heterozygous & $0.67(0.62-0.71)$ & $0.53(0.46-0.61)$ & $0.43 / 0.75$ & $2.29(1.88-2.80)$ \\
\hline & $A D$ versus $\mathrm{MCl}$ & $(9 / 9)$ & Homozygous & $0.93(0.90-0.97)$ & $0.21(0.10-0.33)$ & $0.59 / 0.89$ & $3.94(2.09-7.33)$ \\
\hline \multirow[t]{2}{*}{ Vos et al. $(28,29)$} & $\mathrm{AD}$ versus naMCl & $(73 / 226)$ & N/A & $0.62(0.53-0.71)$ & $0.56(0.37-0.74)$ & $0.25 / 0.86$ & $1.8(0.7-4.7)$ \\
\hline & $\mathrm{AD}$ versus aMCl & (158/399) & N/A & $0.57(0.49-0.64)$ & $0.56(0.46-0.66)$ & $0.40 / 0.71$ & $1.8(1.1-3.0)$ \\
\hline
\end{tabular}

$A D$, Alzheimer's disease; aMCl, amnestic mild cognitive impairment; $A P O E$, apolipoprotein $\mathrm{E} ; \mathrm{HC}$, healthy control; $\mathrm{MCl}$, mild cognitive impairment; naMCl, non-amnestic mild cognitive impairment; OR, odds ratio; PPV/NPV, positive predictive value/negative predictive value.

${ }^{a}$ Ethnic group included if only a particular group was studied.

Corder et al. reported that the $A P O E \& 4$ allele increases the amount of amyloid deposition in a gene dose-dependent manner, which was mirrored by their findings that $\mathrm{AD}$ frequency was increased among APOE $\varepsilon 4$ homozygous individuals compared to those with only one $A P O E \& 4$ allele (91.3 versus $46.6 \%$, respectively) (30). Moreover, the mean age of clinical onset of AD was accelerated in APOE $\varepsilon 4$ homozygous individuals compared to the heterozygotes ( 68 versus 76 years of age, respectively). For those lacking the APOE \&4 gene, AD frequency was found to be $20.4 \%$ with a mean onset age of 84 years. This increase in $\mathrm{AD}$ frequency among $A P O E \& 4$ homozygotes may be due to impaired delivery of cholesterol from astrocytes to neurons where increased cholesterol concentration, especially those found in the membrane, may induce the accumulation of amyloid-beta1-42 $\left(\mathrm{A} \beta_{42}\right)$ through the induction of the $\beta$-secretase pathway (31). In 1996, Saunders et al. sought to quantify the diagnostic value of the APOE $\varepsilon 4$ allele in a real clinical setting (26). For both heterozygous and homozygous patients, they found that the positive predictive value (PPV) was $100 \%$, indicating that those who tested positive for the APOE $\varepsilon 4$ allele truly had AD. However, the negative predictive value (NPV) was low for both groups indicating that the absence of the allele does not necessarily prelude AD (Table 1).

In 2011, Elias-Sonnenschein et al. performed a meta-analysis to determine the predictive value of the APOE $\varepsilon 4$ allele for progression from MCI to AD-type dementia (27). They extracted data from 35 studies involving a grand total of 1,236 $\mathrm{AD}$ patients. They found that the APOE $\varepsilon 4$ allele was a moderately strong predictor of progression from MCI to AD-type dementia, with a PPV of 0.59 for APOE $\varepsilon 4$ homozygotes. However, the PPV was considerably lower for the heterozygotes, and sensitivity was low for both groups (Table 1). These findings suggest that APOE $\varepsilon 4$ may have limited utility in predicting disease progression in AD. Recently, Vos et al. investigated whether potential genetic markers for $\mathrm{AD}$ were differentially distributed in patients with amnestic mild cognitive impairment (aMCI) versus those with non-amnestic mild cognitive impairment (naMCI) (28). They found that the APOE $\varepsilon 4$ allele was similarly prevalent in naMCI and aMCI, at 40 and $47 \%$, respectively. This contrasted with prior studies reporting that the absence of $A P O E \varepsilon 4$ allele was related to less memory impairment and should therefore occur at a much higher frequency in aMCI compared to naMCI (23). Similarly, the sensitivity and specificity of the APOE $\varepsilon 4$ allele in predicting the development of $\mathrm{AD}$ from naMCI and aMCI were very similar (Table 1). This may have been due to the fact that they did not distinguish $A P O E \& 4$ allele carriers into homozygotes versus heterozygotes, and this becomes pertinent since the APOE $\varepsilon 4$ allele behaves in a gene dose-dependent manner (25).

\section{OTHER POTENTIAL GENETIC BIOMARKERS}

A couple of additional genetic markers have also been accorded relatively high ORs in the earlier GWAS studies (http://www.alzgene.org/), as well as a more recent meta-analysis (32), including $B I N 1, C L U$, and PICALM. The BIN1 variant rs6733839 (OR of 1.22; meta $p$-value of $\left.6.9 \times 10^{-44}\right)(32)$ and an additional variant (rs59335482; an insertion of 3 cytosine bases) $28 \mathrm{~kb}$ upstream of $B I N 1$ have been associated with increased $A D$ risk (OR of 1.20 ; $p$-value of $\left.3.8 \times 10^{-11}\right)(33)$. BIN1 is a widely expressed adapter protein that functions in clathrin-mediated endocytosis and endocytic recycling, leading some researchers to believe that $B I N 1$, in turn, functions in A $\beta$ PP metabolism (34). BIN1 is also involved in the regulation of cytoskeleton dynamics, where the tubular membrane structures it forms appear to link the microtubule skeleton with the cellular membrane, leading others to believe that it modulates tau pathology $(35,36)$. PICALM is another widely expressed gene that encodes an adapter protein that functions in clathrin-mediated endocytosis and endocytic recycling, whose polymorphic variants rs3851179 and rs 10792832 have also been associated with AD in GWAS studies (32, 37, 38). Although it is associated with similar functions as BIN1 (i.e., clathrin-mediated endocytosis and endocytic recycling), it exhibits weaker association with LOAD (OR of 0.87 ; meta $p$-value of $9.3 \times 10^{-26}$ for SNP rs10792832) (32). Although the exact role of PICALM in AD pathogenesis is unclear, PICALM has been implicated in APP processing and increased $A \beta$ production in neurons (39). 
Clusterin, also known as apolipoprotein J, or CLU, is another gene significantly associated with LOAD, with an OR of 0.88 and a Bayes factor of 20.1 (http://www.alzgene.org/) and an OR of 0.86 and a $p$-value of $2.8 \times 10^{-25}(32)$. This molecule is abundantly expressed in neurons and astroglia, and tends to colocalize with $\mathrm{A} \beta$, particularly in senile plaques (40). It has been suggested by several studies that $C L U$ plays a protective role in AD pathogenesis through the prevention of $\mathrm{A} \beta$ fibrillization, clearance of $\mathrm{A} \beta$, inhibition of the complement system and neural apoptosis, and promotion of neurite growth (41-43). In particular, the rs11136000 and rs9331896 variants of CLU are associated with reduced $\mathrm{AD}$ frequency (OR of 0.89 and 0.86 , respectively) (38). However, increased levels of CLU have been found in the CSF, frontal cortex, and hippocampus of $\mathrm{AD}$ patients. This apparent contradiction has led to the suggestion that some CLU AD-risk variant carriers may have an increased likelihood of developing $\mathrm{AD}$ later in life due to a diminished neuroprotective action of CLU, which may in turn lead to excessive production of CLU later in life (43). These findings are supported by a more recent study published in 2016 by Weinstein et al. suggesting that the association between plasma CLU levels and the risk of dementia may be dependent on age or an age-related factor (44). In this study, CLU was significantly associated with an increased risk of dementia among elderly subjects ( $>80$ years of age; HR of 6.25 ) but reduced risk of dementia among younger subjects $(<70$ years of age; HR of 0.53 ).

Another genetic variant, only recently reported, also shows promise as a genetic marker of $\mathrm{AD}$. Jonsson et al. analyzed the genomic sequences of 2,261 Icelanders and found rs75932628-T in triggering receptor expressed on myeloid cells 2 (TREM2) to be associated with a 2- to 4.5-fold increased risk of developing nonfamilial $\mathrm{AD}$ (45). The OR was 2.26 for all population controls, 2.92 for population controls 85 years of age or older, and 4.66 for cognitively intact controls (score of 0 on Cognitive Performance Scale) who were 85 years of age or older. The OR of rs75932628-T in the African American population was lower with a value of 1.83 , suggesting that the diagnostic value of this genetic variant may be ethnicity dependent (46). Additionally, another variant of TREM2, rs79011726, exhibited an OR of 2.14 in the African American population. TREM2 is an immune receptor that is found in brain microglial cells (47). Although the exact link between this genetic variant and $\mathrm{AD}$ pathogenesis is unclear, animal studies have indicated that microglia play an important role in how the brain responds to $\mathrm{A} \beta$ plaques (48).

Besides the above players, a few additional genes have also been uncovered through the more recent GWAS International Genomics of Alzheimer's Project (IGAP) (32), including an association in the HLA-DRB5-DRB1 region (OR of 1.11; meta $p$-value of $2.9 \times 10^{-12}$; SNP rs9271192). This region is involved in immunocompetence and histocompatibility and has already been shown to be a risk factor in multiple sclerosis (49). Since its discovery in 2013, one study has explored the role of HLA-DRB5, as well as 11 other newly discovered genetic risk factors $(P T K 2 B$, SORL1, SLC24A4, DSG2, INPP5D, MEF2C, NME8, ZCWPW1, CELF1, FERMT2, and CASS4), in AD pathogenesis. Recently, Yu et al. have reported that brain DNA methylation near HLA-DRB5 was associated with pathological AD ( $p$-value of $\left.5.0 \times 10^{-5}\right)(50)$.
Similar results have also been reported with some of the other novel genetic risk factors documented by IGAP, including SORL1 and SLC24A4, and there will undoubtedly be more studies to come.

\section{COMBINED GENETIC RISK SCORES (GRSs)}

Recently, multiple studies have attempted to combine different genetic risk factors to determine whether a combined genetic panel could more accurately predict AD risk. In 2015, Adams et al. reported that there was a significant interaction between their AD GRS, containing 19 genetic variants, and the age-at-onset of dementia, whereby a stronger genetic effect was noted at earlier ages (51). This AD GRS included some of the genes mentioned above, such as APOE, PICALM, CLU, and BIN1. Adams et al. did not include mutations implicated in familial AD (PSEN1, PSEN2, and $A \beta P P)$, since they wanted to focus on sporadic AD. They found that the novel AD-risk variants identified through GWAS were associated more closely with naMCI (OR 1.25), while $A P O E \& 4$ was better associated with aMCI (1.16) (51),. These results suggest that $\mathrm{AD}$ genes might influence different cognitive domains, but this appears to be in conflict with the 2013 study by Vos et al. particularly for $A P O E \varepsilon 4$, where Vos et al. reported that the $A P O E \& 4$ gene exhibited similar sensitivity and specificity when predicting the development of AD from naMCI and aMCI (Table 1). Nevertheless, Adams et al's results are in agreement with prior studies that reported that the $A P O E \& 4$ gene occurs at higher frequencies in aMCI compared to naMCI (23). Though the association of the AD GRS to MCI and incident dementia is modest, the size of the study $(N=3,605)$ along with the continued follow-up of the initially non-demented subjects over 7-10 years raises hope that this GRS would be of utility in predicting disease development among cognitively normal individuals and that it may lead to a clinically useful test for AD. These findings also warrant a closer look at the effect of each individual genetic locus implicated in $\mathrm{AD}$ pathogenesis, particularly when preceded by MCI, a genetically heterogeneous condition.

In 2015, Sleegers et al. also sought to study the predictive value of GRSs, which included several genes already discussed in this paper: APOE, PICALM, CLU, and BIN1 (52). Four different GRS models were created that are as follows: (1) Model APOE-S, $_{\text {, }}$ (2) $\operatorname{Model}_{\mathrm{APOE}-\mathrm{A}}$, (3) $\mathrm{Model}_{\mathrm{ALL}-\mathrm{WS}}$, and (4) $\operatorname{Model}_{\mathrm{ALL}-\mathrm{WA}}$. The most promising and significant of these models was Model $_{\mathrm{ALL}-\mathrm{WA}}$, which yielded a sensitivity of $55 \%$, specificity of $78 \%$, AUC of 0.70 , and OR of 2.32 for discriminating AD patients, whether familial or sporadic, from healthy controls. Model $_{\text {ALL-WA }}$ was further analyzed for its discriminative ability between familial and sporadic AD. It was found to be a stronger predictor of familial $\mathrm{AD}$ (OR of 3.01 versus 2.14). Logistic regression analysis of Model $_{\text {ALL-WA }}$ also showed an increased risk of $\mathrm{AD}$ with increasing risk score per unit increase in GRS [OR, 2.32 (95\% CI, 2.08-2.58)], with this effect being more prominent in familial AD. Interestingly, the authors found no notable differences in the genetic risk profile in the presence or absence of $A P O E \varepsilon 4$ in their study population. Another recent study examined the interaction between PICALM and APOE and concluded that the PICALM genotype could modulate both brain 
atrophy and cognitive performance in $A P O E \varepsilon 4$ carriers, and may perhaps be responsible for the absence of $A P O E \varepsilon 4$ 's effect on the GRS reported by Sleegers et al. (53). Clearly, genetic interactions between the different genes implicated in $\mathrm{AD}$ and their functional consequences warrant further analysis.

\section{CSF-DERIVED NEUROCHEMICAL BIOMARKERS}

Sampling CSF is a relatively non-invasive method for assessing pathologic alterations occurring within the CNS (9), although, some still consider the required lumbar puncture to be invasive, as there is a small risk of bleeding or brainstem herniation. Due to the CSF's direct contact with the CNS, CSF-derived biomarkers have been studied extensively in $\operatorname{AD}(9,54)$.

\section{CSF A $\beta$ PEPTIDES}

It is well established that senile amyloid plaques, composed largely of $\mathrm{A} \beta$ peptides, accumulate in the cerebral cortex and hippocampus during the early stages of $\operatorname{AD}(54,55)$. The principal $A \beta$ species deposited is $A \beta_{42}$ as it is more hydrophobic and fibrillogenic. These aggregates of $A \beta$ injure synapses, ultimately causing neurodegeneration and dementia (56). This accumulation of $A \beta_{42}$ within the cerebral cortex is hypothesized to be the result of overproduction of $A \beta_{42}$ and/or reduced efflux of $A \beta_{42}$ across the blood-brain barrier into the CSF. Whatever the exact mechanism, the levels of $\mathrm{A} \beta_{42}$ within the CSF are decreased as a result (25). This decrease in baseline CSF levels serves as a potential basis for $\mathrm{AD}$ diagnosis. However, the exact baseline and cutoff value of CSF $A \beta_{42}$ chosen for AD diagnostics has varied between different research group, hence yielding differing diagnostic performance metrics. Recent studies have begun to standardize their assay methods, resulting in more comparable results.

In 2003, Kapaki et al. evaluated the diagnostic potential of $\mathrm{CSF} A \beta_{42}$ as a biomarker of $\mathrm{AD}$ (57). They particularly sought to differentiate $\mathrm{AD}$ from normal aging and other non-AD neurodegenerative dementias (NAND) within the Greek population. They found a 0.5 -fold decrease in CSF $\mathrm{A} \beta_{42}$ levels in AD patients compared with normal aging, whose baseline level was 738 pg/ $\mathrm{ml}$. In 2006, De Jong et al. found a similar fold difference of CSF $\mathrm{A} \beta_{42}$ basal levels in their $\mathrm{AD}$ group compared to healthy controls (58). The latter study attained a sensitivity of 0.93 compared to 0.82 in Kapaki et al.s study, which may be explained by the difference in CSF $A \beta_{42}$ cutoff values used (490 versus 603 pg/ $\mathrm{ml}$, respectively) or other patient-cohort specific differences. In 2010, Mulder et al. carried out a similar analysis of CSF A $\beta_{42}$ and achieved a diagnostic sensitivity and specificity in between that of Kapaki and De Jong et al. (59). This may also be related to the fact that their chosen cutoff value $(550 \mathrm{pg} / \mathrm{ml})$ was also in between the two earlier cutoff values (Table 2).

In a recent study reflecting the shift in Alzheimer's biomarker research focus, Vos et al. did not seek to differentiate AD from healthy controls or NAND. Instead, they studied whether CSF $\mathrm{A} \beta_{42}$ could potentially predict if subjects with aMCI and naMCI would progress to $\mathrm{AD}$ (28). Recent studies have shown that $\mathrm{AD}$ pathology is common in subjects with naMCI; hence, Vos et al. investigated whether the diagnostic performance of this test would differ between these two types of MCI (61). With this CSF test, they were able to achieve slightly better diagnostic capability in predicting $\mathrm{AD}$ arising from aMCI compared to $\mathrm{AD}$ arising from naMCI, although the results were far from being optimal; these findings require independent validation. Although the same sandwich ELISA method (Innotest b-amyloid 1-42; Innogenetics, Ghent, Belgium) was used for CSF $A \beta_{42}$ quantification in all of the above studies, there was variation in the CSF $A \beta_{42}$ cutoff value used for diagnosis, and this may potentially account for the observed differences in diagnostic performance in the different studies. These results are summarized in Table 2.

Although CSF $A \beta_{42}$ has been the most widely studied CSF A $\beta$ peptide in $\mathrm{AD}$, some studies have also investigated the biomarker potential of $A \beta_{40}$, another component of the amyloid plaque that is primarily found in blood vessel walls (62). Gao et al. compared the diagnostic potential of the $A \beta_{40}$ oligomer to that of the $A \beta_{42}$ monomer and found $A \beta_{42}$ monomers to be superior (63). With a chosen cutoff value of $150 \mathrm{pg} / \mathrm{ml}\left(\mathrm{A} \beta_{42}\right.$ monomers are reduced in the CSF of $\mathrm{AD}$ patients), $\mathrm{A} \beta_{42}$ monomers exhibited a diagnostic accuracy of $88 \%$ compared to $83 \%$ for $A \beta_{40}$ oligomers when delineating between healthy controls and $\mathrm{AD}$ patients. An increasing number of studies have also found value in using the ratio of $A \beta_{42}$ to $\mathrm{A} \beta_{40}$ as an $\mathrm{AD}$ biomarker. In 2015, Dumurgier et al. investigated the diagnostic potential of $A \beta_{42 /} A \beta_{40}$ ratio in a multicenter study (64). Overall, the $A \beta_{42} A \beta_{40}$ ratio and isolated $A \beta_{42}$ levels were found to have similar diagnostic accuracy in terms of discriminating $\mathrm{AD}$ from non- $\mathrm{AD}$ subjects with a sensitivity/specificity of $0.73 / 0.78$ and $0.78 / 0.79$, respectively. Interestingly, the use of the $\mathrm{A} \beta_{42 /} \mathrm{A} \beta_{40}$ ratio reduced the number of indeterminate CSF profiles by half and was in better agreement with the clinical diagnosis. These results raise the possibility that CSF $A \beta_{42 /} A \beta_{40}$ ratios may better reflect brain amyloid production and warrant further investigation in longitudinal studies.

\section{CSF TAU PROTEIN}

Along with A $\beta$ senile plaques, NFTs are also present within the hippocampus and cerebral cortex in the early stages of AD. These tangles are composed of filamentous hyperphosphorylated tau protein, whose total concentration is increased in the CSF of AD patients $(10,65)$. Total CSF tau levels have also been found to be increased in $90 \%$ of MCI patients who progressed to AD, implying that CSF tau protein may be a good biomarker for screening MCI patients who may eventually develop AD (65).

Kapaki et al. evaluated the diagnostic potential of total CSF tau protein as a biomarker of $\mathrm{AD}$ versus normal aging and other NAND within the Greek population (57). They observed a 3.5fold increase in CSF t-tau levels in AD patients compared with healthy controls, whose basal level was 140 pg/ml. In 2006, De Jong et al. found a similar fold difference of 3.3 for CSF t-tau levels in their $\mathrm{AD}$ group compared to healthy controls (58). Mulder et al., using a higher cutoff value for CSF tau than De Jong and Kapaki et al., obtained a lower specificity value of 0.78 , although the sensitivity remained high at 0.85 (59). In the same 2013 study cited earlier, Vos et al. also studied whether CSF t-tau protein 
TABLE 2 | Comparison of CSF biomarkers of AD in various studies.

\begin{tabular}{|c|c|c|c|c|c|c|c|c|}
\hline Reference & CSF biomarker & Disease comparison & $\begin{array}{l}\text { No. of cases } \\
\text { (AD/non-AD) }\end{array}$ & Threshold & Specificity (95\% Cl) & Sensitivity (95\% Cl) & AUC & PPV/NPV \\
\hline \multirow[t]{2}{*}{ Kapaki et al. (57) } & $A \beta 1-42$ & $A D$ versus $H C$ & (49/49) & 490 pg/ml & $0.80(0.66-0.90)$ & $0.82(0.68-0.91)$ & 0.87 & $0.92 / 0.6$ \\
\hline & $A \beta 1-42$ & $A D$ versus NAND & $(49 / 15)$ & $435 \mathrm{pg} / \mathrm{ml}$ & $0.80(0.52-0.95)$ & $0.71(0.57-0.83)$ & 0.76 & $0.84 / 0.65$ \\
\hline De Jong et al. (58) & $A \beta 1-42$ & $A D$ versus $H C$ & $(61 / 30)$ & $603 \mathrm{pg} / \mathrm{ml}$ & 0.93 & 0.93 & $\mathrm{~N} / \mathrm{A}$ & $0.97 / 0.88$ \\
\hline Mulder et al. (59) & $A \beta 1-42$ & ProbAD versus $\mathrm{HC}$ & $(131 / 248)$ & $550 \mathrm{pg} / \mathrm{ml}$ & $0.83(0.76-0.89)$ & 0.85 & 0.93 & N/A \\
\hline \multirow[t]{2}{*}{ Vos et al. $(28,29)$} & $A \beta 1-42$ & $\mathrm{AD}$ versus naMCl & (39/226) & $624 \mathrm{pg} / \mathrm{ml}$ & $0.71(0.57-0.85)$ & $0.55(0.33-0.77)$ & $\mathrm{N} / \mathrm{A}$ & $0.48 / 0.76$ \\
\hline & $\mathrm{A} \beta 1-42$ & $\mathrm{AD}$ versus aMCl & (132/399) & $550 \mathrm{pg} / \mathrm{ml}$ & $0.58(0.57-0.85)$ & $0.75(0.64-0.87)$ & N/A & $0.56 / 0.78$ \\
\hline \multirow[t]{2}{*}{ Kapaki et al. (57) } & Total tau & $A D$ versus $H C$ & $(49 / 49)$ & $317 \mathrm{pg} / \mathrm{ml}$ & $0.96(0.86-0.99)$ & $0.88(0.75-0.95)$ & 0.95 & $0.98 / 0.73$ \\
\hline & Total tau & AD versus NAND & $(49 / 15)$ & $437 \mathrm{pg} / \mathrm{ml}$ & 0.93 (0.68-0.99) & $0.71(0.57-0.83)$ & 0.76 & $0.94 / 0.68$ \\
\hline De Jong et al. (58) & Total tau & $A D$ versus $\mathrm{HC}$ & $(61 / 30)$ & $352 \mathrm{pg} / \mathrm{ml}$ & 0.97 & 0.79 & $\mathrm{~N} / \mathrm{A}$ & $0.98 / 0.69$ \\
\hline Mulder et al. (59) & Total tau & $A D$ versus $H C$ & $(131 / 248)$ & $427 \mathrm{pg} / \mathrm{ml}$ & $0.78(0.65-0.91)$ & $0.60(0.39-0.81)$ & $\mathrm{N} / \mathrm{A}$ & $0.57 / 0.80$ \\
\hline \multirow[t]{2}{*}{ Vos et al. $(28,29)$} & Total tau & $A D$ versus naMCl & (39/226) & $427 \mathrm{pg} / \mathrm{ml}$ & $0.78(0.65-0.91)$ & $0.60(0.39-0.81)$ & N/A & $0.57 / 0.80$ \\
\hline & Total tau & $\mathrm{AD}$ versus aMCl & (132/399) & 524 pg/ml & $0.61(0.50-0.72)$ & $0.74(0.62-0.85)$ & $\mathrm{N} / \mathrm{A}$ & $0.57 / 0.77$ \\
\hline \multirow[t]{2}{*}{ Kapaki et al. (57) } & A $\beta 1-42 / T-t a u$ & $A D$ versus $H C$ & $(49 / 49)$ & 2.27 & $0.86(0.73-0.94)$ & $0.96(0.86-0.99)$ & 0.96 & $0.95 / 0.88$ \\
\hline & A $\beta 1-42 / T$-tau & $A D$ versus NAND & $(49 / 15)$ & 1.06 & $1.0(0.78-1.0)$ & $0.71(0.57-0.83)$ & 0.92 & $1.00 / 0.70$ \\
\hline De Jong et al. (58) & A $\beta 1-42 / T-t a u$ & $A D$ versus $H C$ & $(61 / 30)$ & 1.895 & 0.95 & 0.97 & $\mathrm{~N} / \mathrm{A}$ & $0.98 / 0.91$ \\
\hline \multirow[t]{2}{*}{ Vos et al. $(28,29)$} & A $\beta 1-42 / T$-tau & $\mathrm{AD}$ versus naMCl & (39/226) & 0.96 & $0.54(0.38-0.69)$ & $0.90(0.77-1.00)$ & N/A & $0.57 / 0.80$ \\
\hline & A $\beta 1-42 / T-\operatorname{tau}$ & $\mathrm{AD}$ versus aMCl & (132/399) & 0.78 & $0.38(0.27-0.48)$ & $0.98(0.94-1.00)$ & $\mathrm{N} / \mathrm{A}$ & $0.57 / 0.77$ \\
\hline Shaw et al. (60) & $\begin{array}{l}\text { A } \beta 1-42 ; \text { T-tau } \\
\text { with APOE } \varepsilon 4\end{array}$ & $A D$ versus $N C$ & $(100 / 114)$ & 0.34 & 0.80 & 0.98 & 0.94 & $0.86 / 0.97$ \\
\hline
\end{tabular}

A $\beta_{42}$, amyloid-beta1-42 peptide; $A D$, Alzheimer's disease; aMCl, amnestic mild cognitive impairment; HC, healthy control; $M C l$, mild cognitive impairment; naMCl, non-amnestic mild cognitive impairment; NAND, non-AD neurodegenerative dementias; PPV/NPV, positive predictive value/negative predictive value; T-tau, total tau; CSF, cerebrospinal fluid.

could potentially predict if aMCI and naMCI would progress to $\mathrm{AD}$ (28) and found that CSF t-tau was equally predictive of $\mathrm{AD}$ development in both groups.

In addition to CSF t-tau, the main component of NFTs, CSF levels of phosphorylated tau ( $\mathrm{p}$-tau) have also been investigated as an AD biomarker. In 2006, De Jong et al. investigated the diagnostic potential of $\mathrm{p}$-tau for delineating $\mathrm{AD}$ patients and healthy controls. With a cutoff value of $68 \mathrm{pg} / \mathrm{ml}, \mathrm{p}$-tau yielded a sensitivity of 0.75 , specificity of 0.85 , and PPV/NPV of $0.93 / 0.55$. p-tau did not reach the diagnostic value of t-tau in this study. Similar findings were reported by Mulder et al. (59), where a cutoff value of $52 \mathrm{pg} / \mathrm{ml}$ for $\mathrm{p}$-tau yielded a sensitivity of 0.85 and specificity of 0.68 .

The same sandwich ELISA method (Innotest hTAU-Ag; Innogenetics, Ghent, Belgium) was used for all of the above studies investigating CSF t-tau and p-tau. Once again, there was variation in the chosen diagnostic test cutoff values in the different studies, and this could potentially account for the reported differences in the sensitivity and specificity metrics reported in these studies. These results are summarized in Table 2.

\section{CSF A 11-42/TOTAL TAU RATIOS}

Interestingly, some of the above studies suggest that it is actually the ratio of these two CSF molecules that may serve as the ultimate biomarker $(28,66)$, since combining CSF A $\beta 1-42$ and t-tau increased the diagnostic accuracy compared to when they were used alone. This may reflect a physiological relationship between $\mathrm{A} \beta 1-42$ and t-tau that is particularly related to $\mathrm{AD}$ pathogenesis (67). At best, CSF A $\beta 1-42 /$ total tau ratios attained specificity, sensitivity, and PPV values exceeding 95\% in distinguishing AD from healthy control. The NPV of this ratio was about $90 \%$ in distinguishing $\mathrm{AD}$ from healthy controls and 70\% in distinguishing $\mathrm{AD}$ from disease controls (i.e., NAND) (Table 2).

\section{CSF VISININ-LIKE-PROTEIN-1 (VILIP-1)}

Visinin-like-protein-1 has been studied less extensively as a neurochemical biomarker compared to $A \beta_{42}$ and tau protein. The family of visinin-like proteins, which are neuronal calcium sensor proteins, plays a role in both neuroprotective and neurotoxic functions and have been implicated in a number of neurodegenerative diseases $(68,69)$. In particular, VILIP-1 has been identified as a marker of neuronal injury through GWAS and brain injury models where it is released into the CSF from injured neurons (70). Tarawneh et al. (71) have reported that CSF VILIP-1 levels differ between $\mathrm{AD}$ and normal cognitive subjects (520 versus $396 \mathrm{pg} /$ $\mathrm{ml}$, respectively) and correlate with CSF t-tau, p-tau-181, and brain volumes in $\mathrm{AD}$. CSF VILIP-1/A $\beta_{42}$ ratios also differed significantly between $\mathrm{AD}$ and normal cognitive subjects ( 1.55 versus 0.74 , respectively) and correlated with PiB-PET cortical binding potential, which is positively reflective of amyloid load. Clearly, further studies are warranted to compare the performance of this $\mathrm{AD}$ marker with previous biomarker candidates studied in the CSF. For reference, PiB-PET has been used in some studies in parallel with or to confirm CSF A $\beta$ assay results since it is one of the leading neuroimaging tools with the potential to detect and provide quantitative measures of $\mathrm{AD}$ amyloid pathology in vivo at its early stages, with potential for longitudinal tracking $(72,73)$. The potential utility of imaging biomarkers in $\mathrm{AD}$ diagnostics have been reviewed recently $(12,14)$.

\section{CSF YKL-40}

Although markers associated with the underlying neuropathology in $\mathrm{AD}$, namely CSF $\mathrm{A} \beta$ and CSF tau, have remained the top candidates for $\mathrm{AD}$ diagnostics, these markers have also been found to be altered in other disorders such as dementia with Lewy bodies (DLB), frontotemporal dementia (FTD), and vascular 
dementia (VAD). As a result, there has been a concerted effort to identify other biomarkers that can potentially distinguish these different neurological disorders from AD (74). In 2010, Craig-Schapiro reported elevated levels of CSF YKL-40 among very mild and mild-type $\mathrm{AD}$ dementia subjects using ELISA (75). YKL-40, also known as chitinase-3 like-1, is upregulated in various inflammatory conditions and expressed by different cell types such as activated neutrophils, macrophages, chondrocytes, and vascular smooth muscle cells (76). In the brain, it is mainly expressed by astrocytes. Further, in 2015, Wennström et al. reported that CSF YKL-40 was elevated in AD subjects, but not in those with Parkinson's disease or DLB, thus making it a potential distinguishing biomarker between these neurological disorders (77). Hellwig et al. found that YKL-40 had an AUC of 0.74 in distinguishing AD from non-AD subjects (78). However, Janelidze et al. reported no improvement in diagnostic accuracy of either prodromal $\mathrm{AD}$ or $\mathrm{AD}$ dementia when using YKL-40, compared to using core CSF AD biomarkers ( $\mathrm{A} \beta$ and tau), although YKL-40 was selectively increased in $\mathrm{AD}$ and FTD patients compared to the other dementias including DLB, VAD, and Parkinson's disease dementia (79). There is no doubt that future studies will investigate the diagnostic potential of YKL-40 further and confirm if YKL-40 is clinically useful in distinguishing between the different dementias.

\section{CSF NEUROGRANIN (NGRN)}

Another newly reported biomarker candidate is NGRN, a postsynaptic protein expressed mostly in the cortical areas of the brain suggesting a connection to cognition. It is concentrated in the dendritic spines of principal excitatory synapses, whose translocation thereof is impaired in AD; decreased NGRN levels have been observed in the hippocampus and cortex (80). In 2015, Kester et al. reported that CSF NGRN levels were higher in MCI and $\mathrm{AD}$ subjects, compared to cognitively normal subjects (81). This relationship persisted upon follow-up, 3.8 years later. It is believed that the increased levels of CSF NGRN may be secondary to their impaired translocation to dendritic spines. In the same study by Hellwig et al. discussed above, CSF NGRN was found to have an AUC value of 0.85 when distinguishing $\mathrm{AD}$ from non-AD dementia subjects, suggesting that it may be more valuable diagnostically than YKL-40, and that it may also have the potential to distinguish different neuronal disorders, just like YKL-40 (78). In the same study by Janelidze discussed above, no improvement in diagnostic accuracy was noted in assessing prodromal $\mathrm{AD}$ or $\mathrm{AD}$ dementia when using CSF NGRN, compared to using the core CSF AD biomarkers (79). The extent to which CSF NGRN, CSF YKL-40, CSF tau, CSF A $\beta 1-42$, and other potential CSF proteins correlate with each other remains unclear. Clearly, this insight would be significant in constructing future diagnostic panels.

\section{NGRN/BACE1 RATIO}

Other studies have shown that combining CSF biomarkers have improved diagnostic performance, as that seen with CSF A $\beta 1-42$ / tau ratios. In 2016, De Vos et al. investigated NGRN/BACE1 ratio as a potential $\mathrm{AD}$ biomarker and found that it correlated with yearly decline in mini-mental state examination (MMSE) scores in patients with MCI and dementia due to $\mathrm{AD}(\beta=-0.018$ and -0.051 , respectively) (82). $\beta$-site amyloid precursor protein cleaving enzyme 1 (BACE1) is the $\beta$-secretase enzyme required for the production of the neurotoxic $A \beta$ peptide and is thus considered to have a critical early role in the etiology of AD (83). Although extensive diagnostic values are lacking, this study showed this ratio's potential as a prognostic biomarker and will undoubtedly be studied further for possible integration into clinical trials.

\section{CSF A $\beta 1-42$, TOTAL TAU WITH APOE $\varepsilon 4$}

Combining both CSF proteins and genetic biomarkers in 2009, Shaw et al. developed a logistic regression model based on CSF $\mathrm{A} \beta_{42}$, t-tau, and the APOE $\varepsilon 4$ allele (60). Logistic regression analyses were performed using sex, years of education, age at the time of lumbar puncture, $A P O E \varepsilon 4$ allele gene dosage (none, heterozygous, or homozygous), and each of the three CSF biomarkers: A $\beta 42$, t-tau, and phosphorylated tau (p-tau181 ), with backward elimination and insertion into the model that had only $\mathrm{A} \beta_{42}$ and t-tau as variables, in order to identify optimal markers. With these multiple markers, they achieved a specificity of $79.5 \%$, a sensitivity of $98.2 \%$, an ROC AUC value of 94.2\%, and a PPV/NPV of 85.7/97.2\% (Table 2). These sensitivity, NPV, and ROC AUC values were certainly among the highest reported, compared to the performance of the individual CSF biomarkers. However, the associated specificity was closer to the average specificities reported previously, where CSF t-tau, as a single biomarker, had a specificity of $96 \%$. One potential scenario could be to use the combined biomarker panel for initial screening (as it has high sensitivity) followed up by individual biomarker assays that have been shown to have higher specificity metrics.

\section{BLOOD-DERIVED BIOMARKERS}

In addition to studying CSF biomarkers, researchers have sought less invasive sources, such as blood $(10,84)$. Obtaining blood samples is relatively painless and inexpensive, giving potential blood-based biomarkers further advantage over the CSF-based markers. Some of the blood biomarkers appear to be just as diagnostically accurate as the CSF-based and genetic biomarkers though further validation is warranted. The major blood-derived biomarkers for $\mathrm{AD}$ discussed here have been identified through proteomic, lipidomic, and genomic profiling.

\section{DISCOVERY-BASED PLASMA PROTEIN PANELS}

Ray et al. investigated biomarkers that could predict the progression of $\mathrm{MCI}$ to $\mathrm{AD}$ so that early preventative treatment can be delivered to $\mathrm{AD}$-presymptomatic patients $(85,86)$. Using a filter-based, arrayed sandwich ELISA analysis of plasma from presymptomatic to late state $\mathrm{AD}$ and non-demented controls, they were able to identify a large number of elevated proteins within 
these subjects. Using predictive analysis of microarrays, Ray et al. further narrowed down potential candidates to a predictor panel of 18 proteins (86). With this 18 -protein panel, they were able to achieve a diagnostic accuracy of $90 \%$ in distinguishing $\mathrm{AD}$ and MCI subjects, where $81 \%$ of MCI subjects were accurately identified to progress to $\mathrm{AD}$ after a 2- to 6-year follow-up period (Table 3). They were classified with $90 \%$ positive agreement for the $\mathrm{AD}$ samples and $88 \%$ negative agreement for the non-AD samples. Although published in 2007, these proteins have not been replicated widely, while one study has reported no difference in a majority of these 18 proteins between $\mathrm{AD}$ and healthy subjects (85). In 2014, in an independent study, Hye et al. achieved a high diagnostic accuracy with a 10-protein panel (87). Of these proteins, ICAM-1 was the only protein that overlapped with Ray et al.'s 18-protein panel.

In their 2006 study, Hye et al. performed proteomic analysis of plasma samples from $\mathrm{AD}$ and healthy elderly subjects using isoelectric focusing followed by polyacrylamide gel electrophoresis (93). A set of 15 proteins was identified and validated using western blotting. For diagnostic analysis, the profile of these 15 proteins in $\mathrm{AD}$ and healthy elderly subjects were measured using 2-D gel electrophoresis (2-DGE). Further support vector machine analysis of the 2-DGE data yielded a sensitivity of $56 \%$ and specificity of $80 \%$ for AD diagnosis (93).

In a later study, they analyzed plasma samples from AD, MCI, and elderly non-demented subjects using multiplex bead assays (Luminex xMAP) incorporated in 7 MILLIPLIEX MAP panels (87). In particular, Hye et al. focused on 26 proteins that had been previously identified as potential AD biomarkers. These biomarkers include proteins from their earlier study in 2006 [ceruloplasmin, complement factor $\mathrm{H}(\mathrm{CFH})$, and serum amyloid P-component precursor (SAP)] and proteins from the 18-protein panel reported by Ray et al. (93). Out of the 26 plasma proteins tested, Hye et al. found only 2 proteins, ApoE and CFH, to be significantly different between $\mathrm{AD}$ and controls.

In this same study, Hye et al. then proceeded to identify plasma proteins that could predict the progression of MCI to AD, which was assessed based on the degree of hippocampal atrophy. Using multivariate linear regression analysis, they identified six proteins that predicted $19.5 \%$ of hippocampal volume loss in subjects with MCI: CLU, neuron-specific enolase (NSE), TTR, vascular adhesion molecule 1, and SAP. In addition, seven proteins were identified that predicted $11.9 \%$ of hippocampal volume loss in subjects with AD: APOA1, alpha-1 antitrypsin (A1AT), ApoC3, brain-derived neurotrophic factor, AB40, plasminogen activator inhibitor-1, and NSE. They reasoned that since these proteins reflected pathological load, they might also predict conversion from pre-disease states (i.e., MCI) to clinical dementia (i.e., AD). Applying the Naïve Bayes simple machine learning approach to a test set, they found that the average time of conversion of $\mathrm{MCI}$ to $\mathrm{AD}$ was approximately 1 year where a combination of 10 plasma proteins (TTR, CLU, cystatin C, A1AcidG, ICAM-1, CC4, pigment epithelium-derived factor, A1AT, RANTES, and ApoC3) coupled with the APOE $\varepsilon 4$ genotype yielded the greatest predictive potential with $85 \%$ sensitivity, $88 \%$ specificity, $0.87 \%$ accuracy, and 68.8/95\% PPV/NPV (Table 3). This protein panel did not quite reach the $90 \%$ diagnostic accuracy reported in Ray et al's study, but one can certainly envision further fine tuning of these protein panels to attain better diagnostic performance in future studies.

\section{PROTEIN PANEL COMBINED WITH APOE \&4 ALLELE}

In 2014, Kiddle et al. reviewed 21 discovery or panel-based proteomic studies aimed at identifying protein biomarkers in

TABLE 3 | Comparison of blood biomarkers of AD in various studies.

\begin{tabular}{|c|c|c|c|c|c|c|c|c|}
\hline Reference & Blood biomarker & $\begin{array}{l}\text { Disease } \\
\text { comparison }\end{array}$ & $\begin{array}{c}\text { No. of } \\
\text { cases (AD/ } \\
\text { non-AD) }\end{array}$ & Accuracy & $\begin{array}{l}\text { Specificity } \\
\text { (95\% Cl) }\end{array}$ & $\begin{array}{l}\text { Sensitivity } \\
(95 \% \mathrm{Cl})\end{array}$ & AUC & PPV/NPV \\
\hline Ray et al. (86) & 18-protein panel & $A D$ versus $\mathrm{MCl}$ & $(22 / 17)$ & 0.90 & N/A & N/A & N/A & N/A \\
\hline Hye et al. (87) & 10-protein panel with $A P O E \varepsilon 4$ & $A D$ versus $M C l$ & $(476 / 220)$ & 0.87 & 0.88 & 0.85 & 0.84 & $0.69 / 0.95$ \\
\hline \multirow[t]{2}{*}{ Kiddle et al. (88) } & Covariates $^{a}$ & $A D$ versus $H C$ & $(80 / 53)$ & 0.71 & 0.74 & 0.70 & N/A & $0.89 / 0.45$ \\
\hline & $\begin{array}{l}\text { Replicated proteins with } \\
\text { covariates }^{a}\end{array}$ & $A D$ versus $H C$ & $(80 / 53)$ & 0.77 & 0.72 & 0.80 & $\mathrm{~N} / \mathrm{A}$ & $0.83 / 0.68$ \\
\hline \multirow{2}{*}{$\begin{array}{l}\text { Mapstone et al. } \\
\text { (89) }\end{array}$} & 10 metabolite panel & $\mathrm{aMCl} / \mathrm{AD}$ versus $\mathrm{HC}$ & $(21 / 20)$ & $\mathrm{N} / \mathrm{A}$ & $\mathrm{N} / \mathrm{A}$ & $\mathrm{N} / \mathrm{A}$ & 0.77 & $\mathrm{~N} / \mathrm{A}$ \\
\hline & 10 metabolite panel & $\begin{array}{l}\text { Converters pre versus } \\
\mathrm{HC}\end{array}$ & $(10 / 20)$ & N/A & 0.90 & 0.90 & 0.92 & $\mathrm{~N} / \mathrm{A}$ \\
\hline \multirow[t]{2}{*}{$\begin{array}{l}\text { Leidinger et al. } \\
\text { (90) }\end{array}$} & 12-miRNA signature & $A D$ versus $H C$ & $(48 / 22)$ & $\begin{array}{c}0.933 \pm 0.046 \\
(0.924-0.942)\end{array}$ & $\begin{array}{l}0.951 \pm 0.054 \\
(0.941-0.962)\end{array}$ & $\begin{array}{l}0.915 \pm 0.058 \\
(0.904-0.927)\end{array}$ & $\mathrm{N} / \mathrm{A}$ & $0.949 / 0.918$ \\
\hline & 12-miRNA signature & $A D$ versus $M C l$ & $(94 / 18)$ & $\begin{array}{l}0.756 \pm 0.078 \\
(0.741-0.772)\end{array}$ & $\begin{array}{l}0.767 \pm 0.083 \\
(0.751-0.784)\end{array}$ & $\begin{array}{l}0.746 \pm 0.097 \\
(0.727-0.765)\end{array}$ & $\mathrm{N} / \mathrm{A}$ & $0.779 / 0.724$ \\
\hline $\begin{array}{l}\text { Bhatnagar et al. } \\
(91)\end{array}$ & miRNA-34c & $A D$ versus $H C$ & $(25 / 27)$ & 0.94 & 0.96 & 0.92 & 0.99 & $0.958 / 0.923$ \\
\hline Cheng et al. (92) & $\begin{array}{l}16 \text { miRNA signatures with } \\
A P O E \varepsilon 4\end{array}$ & $A D$ versus $H C$ & $(16 / 36)$ & $\mathrm{N} / \mathrm{A}$ & 0.77 & 0.87 & $\mathrm{~N} / \mathrm{A}$ & $\mathrm{N} / \mathrm{A}$ \\
\hline
\end{tabular}

AD, Alzheimer's disease; aMCl, amnestic mild cognitive impairment; APOE, apolipoprotein E; Converters pre, phenoconverters prior to conversion; HC, healthy control; MCI, mild cognitive impairment; naMCl, non-amnestic mild cognitive impairment; NAND, non-AD neurodegenerative dementias; PPV/NPV, positive predictive value/negative predictive value; miRNA, microRNA.

${ }^{a}$ The covariates examined included age at disease onset, gender, and presence of APOE $\varepsilon 4$ allele. 
AD. Four of these markers ( $\alpha-1$ antitrypsin, $\alpha$-2-macroglobulin, APOE, and complement C3) were replicated in 5 of the 21 independent studies despite the use of different methodologies (88). Certain covariates, such as the age of disease onset and gender, coupled with the presence of APOE $\varepsilon 4$ allele had some predictive capability (Table 3). Combining these covariates with these four most highly replicated blood protein biomarkers improved the predictive potential (Table 3 ). These results indicate that combining biomarker leads from multiple OMICs approaches (e.g., proteomics and genomics) may lead to $\mathrm{AD}$ biomarkers with improved predictive performance. The biomarkers used in these studies also represent the molecules that have been validated in the largest numbers of independent patient cohorts.

\section{DISCOVERY-BASED BLOOD LIPID PANELS}

Recently Mapstone et al. reported a set of 10 phospholipids from peripheral blood that predicted phenoconversion to either aMCI or AD within 2-3 years, with over 90\% accuracy (89). These researchers performed an untargeted metabolomic analysis of 124 plasma samples from aMCI/AD (including postphenoconverters) that were taken at the start of the study, and 3 years later. They then used tandem mass spectrometry to identify 10 metabolites that constituted a discriminatory signature: phosphatidylcholines (PCs) [PC diacyl (aa) C36:6, PC aa C38:0, PC aa C38:6, PC aa C40:1, PC aa, C40:2, PC aa C40:6, PC acylalkyl (ae) C40:6], lysophosphatidylcholine (lysoPC a C18:2), and acylcarnitines (ACs) [propionyl AC (C3) and C16:1-OH]. These 10 lipids were reduced in the plasma of the Converter pre $_{\text {group }}$ compared to the healthy controls, and they remained so even after phenoconversion to aMCI/AD (Converters post $_{\text {) }}$ (Table 3). This 10-lipid panel still needs to be validated in independent studies. Also, the biological relevance of these lipids to the pathogenesis of $\mathrm{AD}$ warrants careful evaluation.

\section{DISCOVERY-BASED BLOOD microRNA (miRNA) SIGNATURES}

Several groups have attempted to identify potential miRNA signatures for $\operatorname{AD}(94,95)$. One of the highest diagnostic accuracies among these studies was reported by Leidinger et al., who identified a panel of 12 miRNAs through NGS of blood miRNA transcriptomes from $\mathrm{AD}$ patients, MCI patients, and healthy controls (90). This 12-miRNA signature was validated by RT-qPCR in a group of 202 patients suffering from other neurological disorders, which included MCI. While some blood miRNA were reduced in AD (hsa-let-7f-5p, hsa-miR-1285-5p, hsa-miR-107, hsa-miR-103a-3p, hsa-miR-26b-Sp, hsa-miR-26a-Sp, and hsamiR-532-Sp), others were elevated (hsa-miR-151a-3p, brainmir-161, hsa-let-7d-3p, brain-miR-112, and hsa-miR-5010-3p), when compared to the healthy controls. Leidinger et al. were able to differentiate between $\mathrm{AD}$ and controls with an accuracy of $93 \%$, a specificity of $95 \%$, and a sensitivity of $92 \%$, while the differentiation of $\mathrm{AD}$ from other neurological diseases (MCI, Parkinson's disease, multiple sclerosis, and major depression) attained accuracies between 74 and 78\% (Table 3). Though these results are promising, further independent validation is warranted.

In 2014, Bhatnagar et al. reported that miRNA-34c is more highly expressed in the plasma ( 0.29 versus 0.1$)$ and peripheral blood mononuclear cells ( 0.08 versus 0.07 ) of AD patients compared to healthy controls (91). They then analyzed whether blood miRNA-34c could distinguish AD subjects from age-matched healthy counterparts. They achieved relatively high diagnostic accuracies, compared to other AD miRNA biomarker studies, with a sensitivity of 0.92 , a specificity of 0.96 , and a PPV/ NPV of $0.958 / 0.923$. Validation in independent cohorts and comparison to other neurological disease controls are warranted. Interestingly, earlier studies have shown that miRNA-34c plays a role in the repression of genes involved in cell survival/apoptosis and neuroprotective signaling $(96,97)$.

\section{MIRNA SIGNATURE COMBINED WITH APOE \&4 ALLELE}

In 2014, Cheng et al. identified a set of 16 miRNAs in the plasma of $\mathrm{AD}$ that could serve as a potential disease signature (92). This 16 miRNA signature was created using NGS with qRT-PCR validation, a method used previously by Leidinger et al., though, there was no overlap between the miRNA signatures uncovered in these two studies (90). While some miRNA were reduced in AD (hsa-miR-1306-5p, hsa-miR-342-3p, and 15b-3p), others were elevated (hsa-miR-361-5p, hsa-miR-30e-5p, hsa-miR-93-5p, hsa-miR-15a-5p, hsa-miR-143-3p, hsa-miR-335-5p, hsa-miR106b-5p, hsa-miR-101-3p, hsa-miR-424-5p, hsa-miR-106a-5p, hsa-miR-18b-5p, hsa-miR-3065-5p, hsa-miR-20a-5p, and hsamiR-582-5p), when compared to the healthy control subjects. Combining this deregulated 16 miRNA signature with the presence of the APOE $\varepsilon 4$ allele, Cheng et al. were able to discriminate $\mathrm{AD}$ subjects from healthy subjects with $77 \%$ specificity and $87 \%$ sensitivity (Table 3). The diagnostic parameters of this study may be less optimal than that of Leidinger et al. (77\% specificity and $87 \%$ sensitivity versus $95 \%$ specificity and $92 \%$ sensitivity, respectively), even with the integration of the APOE $\varepsilon 4$ allele, possibly due to a smaller cohort size ( $n=60$ versus $n=202$, respectively). All of the above miRNA studies warrant independent validation and analysis in longitudinal data sets so as to identify common, reproducible themes. This becomes particularly pertinent given that there was no overlap between the findings of these two reports.

\section{PLASMA A 1-42/A $\beta 1-40$ RATIOS}

Several studies have examined the predictive ability of plasma $\mathrm{A} \beta$ levels. This is not surprising given that CSF A $\beta$ levels and $\mathrm{A} \beta$ accumulation, as determined by $\mathrm{PiB}-\mathrm{PET}$, are validated $\mathrm{AD}$ biomarkers $(5,7,8,29,98)$. However, recent findings on the relationship between $\mathrm{AD}$ pathogenesis and plasma $\mathrm{A} \beta$ levels have been contradictory. Whereas some argue that an increase in the plasma $A \beta_{42} / A \beta_{40}$ ratio is related to an increased risk of developing $\mathrm{AD}$ (99), others report that it is actually the reduction of plasma 
$\mathrm{A} \beta_{42} / \mathrm{A} \beta_{40}$ ratio that increases risk (72, 100-102). Interestingly, positron emission tomography (PET) measures of brain amyloid burden does show an association between reduced plasma $A \beta_{42} /$ $\mathrm{A} \beta_{40}$ and increased brain amyloid load $(72,102)$. In addition, a recent study by Chouraki et al., examining the levels of plasma $A \beta_{42}$ and $A \beta_{40}$ in 2,189 dementia-free individuals over an 8-year period, found that lower levels of plasma $A \beta_{42} / A \beta_{40}$ ratio were associated with an increased risk of developing dementia or incident $\mathrm{AD}$ (100). Likewise, Fei et al. followed the plasma $A \beta_{42} / A \beta_{40}$ ratios of 588 subjects with MCI over 4-6 years to ascertain if these ratios can be used to identify those who may convert to AD. Fei et al. reported that plasma $A \beta_{42} / A \beta_{40}$ ratios exhibited a sensitivity of $85.7 \%$ and specificity of $69.7 \%$ in this respect (103). Although the diagnostic value of plasma $A \beta_{42} / A \beta_{40}$ ratios did not quite surpass that of CSF $A \beta_{42}$ used alone, these results call for further investigation of plasma biomarkers that may be reflective of amyloid load.

\section{BLOOD BIOMARKERS OF NEOCORTICAL AMYLOID BURDEN (NAB) IN AD}

Along the same vein, researchers have searched for other bloodbased biomarkers that may reflect $\mathrm{NAB}$, a pathophysiology known to increase the risk of $\operatorname{AD}(7,104,105)$. With these particular NAB biomarkers, researchers hope to identify an optimal window of treatment with anti-A $\beta$ therapies (106). Very recently, Ashton et al. reported that a single blood protein, fibrinogen $\gamma$-chain (FGG), selected from 17 discovery candidates, predicted high NAB when combined with age, yielding a sensitivity of $59 \%$ and specificity of $78 \%$. High NAB was considered for standardized uptake value ratios (SUVR) greater than 1.3 in PiB-PET scans, a cutoff value supported by previous studies (105). Other studies argue that an SUVR greater than 1.5 is a more appropriate cut off, but whether this difference has a significant impact on diagnostic performance is yet to be determined (107). Whereas plasma $A \beta_{42} / A \beta_{40}$ ratios exhibit moderately high sensitivity and moderately low specificity, FGG exhibits the inverse diagnostic relationship (104).

Voyle et al. also noted the promise of FGG. Very recently, they constructed a 5-metabolic feature panel, further enriched by the addition of FGG, to identify those with high NAB. These 5-metabolic features were selected from an initial number of 3,196, after rigorous metabolomic analysis using multiple metabolic feature models (108). However, only four of the five metabolites, phosphatidylcholine (PCaa 36:6), PE 39:7, anandamide, and anandamide isotope, were putatively identified. When combined with FGG, this 4-plex metabolic panel identified high-NAB subjects with a sensitivity of $71 \%$, specificity of $84 \%$, and accuracy of $79 \%$, diagnostic values that exceed that of previously reported bloodbased biomarker for NAB. Collectively, these studies indicate that researchers are close to identifying blood-based biomarkers of NAB with accuracies approaching $80 \%$.

\section{LONGITUDINAL STUDIES}

Recent studies have shown that approximately $30 \%$ of agematched HC individuals have preclinical $\mathrm{AD}$ based on two currently validated biomarkers, $\mathrm{A} \beta$ in PiB-PET measurements or $A \beta$ in the $\operatorname{CSF}(6,8,98)$. This frequency does differ between reports, likely due to methodological differences between studies (109). These results and results from other clinicopathological and biomarker studies support the existence of a long preclinical stage during which $\mathrm{AD}$ pathologies develop, preceding the appearance of cognitive symptoms. Because of this, the primary focus of Alzheimer's research has shifted from differentiation between HC and $\mathrm{AD}$ to determining the rates of cognitive decline in subjects who have preclinical, prodromal, or clinical AD. Through longitudinal studies, researchers envision that an effective treatment window may emerge, which could potentially permit therapeutic intervention, including anti-A $\beta$ therapies (106).

\section{BASELINE CSF BIOMARKERS VERSUS LONG-TERM COGNITIVE DECLINE}

Based on their promising results in 2011, Tarawneh et al. examined the long-term prognostic potential of CSF VILIP-1 and VILIP-1/ $\mathrm{A} \beta_{42}$ ratios over a period of 2.6 years among $\mathrm{AD}$ patients $(71,110)$. CSF was only collected once at the beginning of the study and analyzed for t-tau, p-tau (or p-tau-181), A $\beta_{42}$, and VILIP-1. To assess the progression of cognitive decline, $60 \mathrm{AD}$ subjects were cognitively assessed using the clinical dementia rating sum of boxes (CDR-SB), annually, with an average of 3 cognitive assessments per subject. The CDR has high inter-rater reliability, is sensitive to clinical progression, and is highly predictive (93\%) of autopsy-confirmed AD (111, 112 ). Once $\mathrm{AD}$ diagnosis using CDR-SB was confirmed (using a cut off of 0.5), a psychometric test battery assessing a broad spectrum of cognitive functions was administered to all subjects. This test quantified the episodic memory composite, the semantic memory composite, the working memory composite, the visual spatial composite, and the global psychometric composite of all subjects.

Not surprisingly, higher basal levels of all the CSF biomarkers examined were associated with an increased rate of decline. However, CSF VILIP-1 and p-tau-181 proteins predicted the greatest decline (1.61 and 1.583, respectively) within the upper tercile group (with cut offs at 560 and $93 \mathrm{pg} / \mathrm{ml}$, respectively), while in the lower tercile group, CSF VILIP-1 and t-tau protein predicted the greatest decline (0.852 and 0.828 , respectively) of CDR-SB. For CSF VILIP- $1 / A \beta_{42}$ ratios, the rate of CDR-SB decline for both the upper and lower tercile group were the lowest among all the CSF biomarkers assessed, although still discernable. When analyzing the rate of decline for global psychometric and episodic memory composite scores, CSF VILIP- $1 / \mathrm{A} \beta_{42}$ ranked highest ( 0.615 and 0.674 , respectively), followed by CSF p-tau- $181 / \mathrm{A} \beta_{42}$ (0.594 and 0.659 , respectively). This study's conclusion that CSF VILIP-1 and CSF VILIP-1/A $\beta_{42}$ ratio can predict global cognitive changes resonates well with findings from other studies, as described below.

\section{BASELINE DISEASE STAGE VERSUS LONG-TERM COGNITIVE DECLINE}

Vos et al. investigated the prevalence and long-term outcome of preclinical $\mathrm{AD}$ based on new classification criteria employing 
preclinical disease stages, where stage 1 subjects were cognitively normal individuals with abnormal amyloid markers, stage 2 subjects had abnormal amyloid and neuronal injury markers with no subtle cognitive changes, and stage 3 subjects had abnormal amyloid and neuronal injury markers with subtle cognitive changes (29). Three hundred eleven subjects underwent annual cognitive assessment, which included CDR and CDR-SB, MMSE, and a psychometric test battery. At the beginning of the study, all groups, including preclinical $\mathrm{AD}$, were considered to have a CDR of 0 , meaning that no dementia was present. Vos et al. sought to map their progression to a CDR $\geq 0.5$ (onset of symptomatic $\mathrm{AD})$ over a 14-year period. CSF samples were obtained from all subjects and analyzed for t-tau, p-tau-181, and $\mathrm{A} \beta_{42}$ levels. APOE $\varepsilon 4$ allele presence was also recorded, with stage 3 subjects having the largest prevalence of $A P O E \varepsilon 4$ positivity (69\%). Indeed, stage 3 subjects showed the highest rate of progression to clinical dementia ( $56 \%$ after 5 years), followed by stage 2 (26\%), stage $1(11 \%)$, and the normal subjects (2\%). This increased rate of progression to clinical dementia with increased preclinical stage score was also reflected by their progressively increasing deficits of CSF A $\beta_{42}$ levels (355, 350, $321 \mathrm{pg} / \mathrm{ml}$ for stages 1, 2, and 3 , respectively). These studies underscore the importance of factoring in baseline clinical symptoms, laboratory markers, and genotype in order to prognosticate future disease progression. Such a multi-pronged panel could also be of immense utility in tracking treatment response in future clinical trials.

\section{CSF BIOMARKER LEVELS VERSUS EOAD PROGRESSION}

In 2014, Fagan et al. performed a longitudinal investigation of preclinical biomarkers based on clinicopathological evidence suggesting that the early pathological events of AD occur years before the onset of cognitive symptoms $(8,113)$. This study differed significantly from the other studies discussed above in that they studied subjects who were autosomal-dominant for $\mathrm{AD}$ and thus had EOAD in contrast to LOAD.

In their follow-up study, they enlisted a large cohort of 146 mutation carriers (MCs) and 96 mutation non-carriers (NCs) from the dominantly inherited Alzheimer network, spanning a wide range of estimated number of years to symptom onset. They analyzed longitudinal CSF samples from a subset of 37 individuals (11 NCs and $26 \mathrm{MCs}$ ) examined every 5 years and found that in asymptomatic MCs, the serial change in CSF biomarkers was similar to those seen in previous cross-sectional LOAD studies, i.e., elevations in CSF t-tau, p-tau-181, and VILIP-1 and reduction in CSF A $\beta_{42}$. The observation of CSF VILIP-1 elevations in MCs at least 15 years before their estimated age at symptom onset (EAO), with concentrations being even higher in individuals who were closer to their EAO, suggests a robust phase of neuronal injury and/or death that begins before the onset of cognitive symptoms. However, once the MCs reached their age of AD onset, Fagan et al. observed a decrease in CSF markers of neuronal injury/death (i.e., CSF t-tau, CSF p-tau-181, and VILIP-1) as time progressed. The rate of longitudinal change (adjusted for gender and APOE $\varepsilon 4$ genotype) was documented as +6.90 to $-10.79 \mathrm{pg} / \mathrm{ml}$ per year for CSF tau, 1.34 to $-6.62 \mathrm{pg} / \mathrm{ml}$ per year for CSF p-tau-181, and -0.903 to $-14.60 \mathrm{pg} / \mathrm{ml}$ per year for VILIP-1. This longitudinal evolution suggests that once these neuronal injury markers reach their peak release, which may occur during age at symptom onset, the rate of release of these markers may then slow down, in line with a progressive decline in neuronal injury/death. This study provides an impetus for further longitudinal studies of LOAD, with systematic serial monitoring of not only CSF markers, but also blood-derived biomarkers.

\section{COMBINED GRS VERSUS RISK OF CONVERSION/RAPID PROGRESSION TO $\mathrm{MCl}$}

In 2013, Rodríguez-Rodríguez et al. evaluated whether a combined GRS, including APOE, BIN1, PICALM, and CLU, is associated with either risk of conversion or with rapid progression from $\mathrm{MCI}$ to $\mathrm{AD}$ (114). They followed 288 subjects with MCI over a mean period of 26.3 months and identified $118 \mathrm{MCI}$-converters to AD and $170 \mathrm{MCI}-$ non-converters. Perhaps not surprisingly, APOE $e 4$ was significantly associated with conversion risk $(\mathrm{OR}=4.63)$ and rapid progression (HR 1.77), while CLU was associated with decreased conversion risk (OR 0.25), which is in agreement with previous studies suggesting that it has a neuroprotective role in $\mathrm{AD}$ pathogenesis (41). In contrast, Rodríguez-Rodríguez et al. found no association between the combined GRS and the risk of conversion from MCI to AD. However, they did find that those who did convert and carried six risk alleles or more progressed about twice as quickly to AD than those who carried less than six risk alleles, with the acceleration of progression being an average of 5 months. This is somewhat of an improvement compared to using $A P O E$ e 4 alone (HR 1.77). Unfortunately, the correlation between GRS $(115,116)$ and severity of AD development was not explored. Studies of this nature, which factor in multiple biomarkers, including the GRS, CSF, and blood-based biomarkers, will be useful for defining disease progression with better accuracy and possibly for designing interventional therapies.

\section{CLINICAL TRIALS}

There has been an increasing push to evaluate potential AD biomarkers not only for diagnostic accuracy in the preclinical stages of $\mathrm{AD}$ but also in their ability to serve as prognostic markers and theranostic markers of response to AD treatment (117). As mentioned previously, disease-modifying treatments are most likely to have maximal benefit during the preclinical stages of $\mathrm{AD}$; hence, the focus of drug development has shifted from the dementia stage of the disease where previous treatment methods were found to yield only modest if any benefit $(118,119)$. Compared to the wealth of available biomarkers, very few of these have been factored into clinical trials. Where biomarkers have been utilized in clinical drug studies, they have served as inclusion criteria for $\mathrm{AD}$ pathology presence and trackers of biological effects of treatment. Out of these studies, the bapineuzumab and solanezumab studies, which utilized PiB-PET and CSF biomarkers, initially showed promising results and progressed to phase III 
trials, where they ultimately failed $(115,116,120,121)$. Despite these negative results, biomarkers are clearly valuable tools in clinical trials, as is becoming evident from lessons learned in other fields. The bottleneck is in deciding what the optimal biomarkers to use are. With this in mind, there has been a call for more longitudinal studies on biomarker trajectories, linking neuropathology to biomarkers, and discovering novel biomarkers reflecting other disease processes downstream of initial AD pathology (117). Undoubtedly, the use of the most promising CSF and blood biomarkers arising from these studies, alongside with concurrent neuroimaging biomarkers, is likely to play an increasingly important role in future clinical trials.

\section{CONCLUSION}

A clinically useful biomarker should preferentially have a sensitivity, specificity, PPV, and NPV exceeding 90\%. Using these criteria, several biomarkers discussed above, including CSF A $\beta 1-42 / \mathrm{t}$-tau ratio (Table 2), 12-miRNA signature (Table 3), and miRNA-34c (Table 3), look promising as all of their diagnostic parameters exceed $90 \%$. In addition, CSF A $\beta_{42}$ and the blood-based 10 lipid test have both yielded reasonable sensitivity and specificity

\section{REFERENCES}

1. Alzheimer's Association. Alzheimer's Disease Facts and Figures. (2013). Available from: https://www.alz.org/downloads/facts_figures_2013.pdf

2. Alzheimer's Disease Education and Referral (ADEAR) Center. Alzheimer's Disease Fact Sheet. NIH Publication No. 11-6423 (2011). Available from: https://www.nia.nih.gov/alzheimers/publication/alzheimers-disease-factsheet

3. Galluzzi S, Geroldi C, Amicucci G, Bocchio-Chiavetto L, Bonetti M, Bonvicini $\mathrm{C}$, et al. Supporting evidence for using biomarkers in the diagnosis of MCI due to AD. J Neurol (2013) 260:640-50. doi:10.1007/s00415-0126694-0

4. Murphy MP, Levine H III. Alzheimer's disease and the amyloid-beta peptide. J Alzheimers Dis (2010) 19:311-23. doi:10.3233/JAD-2009-1221

5. Baird AL, Westwood S, Lovestone S. Blood-based proteomic biomarkers of Alzheimer's disease pathology. Front Neurol (2015) 6:236. doi:10.3389/ fneur.2015.00236

6. Mormino EC, Betensky RA, Hedden T, Schultz AP, Amariglio RE, Rentz DM, et al. Synergistic effect of $\beta$-amyloid and neurodegeneration on cognitive decline in clinically normal individuals. JAMA Neurol (2014) 71:1379-85. doi:10.1001/jamaneurol.2014.2031

7. Rowe CC, Ng S, Ackermann U, Gong SJ, Pike K, Savage G, et al. Imaging B-amyloid burden in aging and dementia. Neurology (2007) 68:1718-25. doi:10.1212/01.wnl.0000318046.06992.24

8. Sperling R, Mormino E, Johnson K. The evolution of preclinical Alzheimer's disease: implications for prevention trials. Neuron (2014) 84:608-22. doi:10.1016/j.neuron.2014.10.038

9. Fiandaca MS, Mapstone ME, Cheema AK, Federoff HJ. The critical need for defining preclinical biomarkers in Alzheimer's disease. Alzheimers Dement (2014) 10:S196-212. doi:10.1016/j.jalz.2014.04.015

10. Humpel C. Identifying and validating biomarkers for Alzheimer's disease. Trends Biotechnol (2011) 29:26-32. doi:10.1016/j.tibtech.2010.09.007

11. Onos KD, Sukoff Rizzo SJ, Howell GR, Sasner M. Toward more predictive genetic mouse models of Alzheimer's disease. Brain Res Bull (2016) 122:1-11. doi:10.1016/j.brainresbull.2015.12.003

12. Ruan Q, D’Onofrio G, Sancarlo D, Bao Z, Greco A, Yu Z. Potential neuroimaging biomarkers of pathologic brain changes in mild cognitive impairment and Alzheimer's disease: a systematic review. BMC Geriatr (2016) 16:104. doi:10.1186/s12877-016-0281-7 values, with $\mathrm{A} \beta_{42}$ alone yielding a PPV, at or greater than $90 \%$ (Tables $\mathbf{1}$ and 2, respectively). These biomarkers, particularly in combination, warrant further validation in multiple independent patient cohorts. Although initial results are promising, miRNA biomarkers in particular will need subsequent replication studies since this biomarker approach is newer. More importantly, efforts are warranted to mine newer biomarkers using more advanced screening platforms, including those that allow for global scans of proteins, peptides, and metabolites, in blood as well as CSF. With accelerated research, one is hopeful that improved, easily measurable biomarkers that can predict the rates of cognitive decline and $\mathrm{NAB}$ in subjects who have preclinical, prodromal, or clinical AD will emerge.

\section{AUTHOR CONTRIBUTIONS}

RH contributed to the drafting of the manuscript. CM worked on the organization, direction, and editing of the manuscript.

\section{FUNDING}

Funding was provided by R01 DK81872.

13. Sabbagh JJ, Kinney JW, Cummings JL. Alzheimer's disease biomarkers: correspondence between human studies and animal models. Neurobiol Dis (2013) 56:116-30. doi:10.1016/j.nbd.2013.04.010

14. Salvatore C, Cerasa A, Battista P, Gilardi MC, Quattrone A, Castiglioni I. Magnetic resonance imaging biomarkers for the early diagnosis of Alzheimer's disease: a machine learning approach. Front Neurosci (2015) 9:307. doi:10.3389/fnins.2015.00307

15. Panegyres PK, Chen H-Y. Differences between early and late onset Alzheimer's disease. Am J Neurodegener Dis (2013) 2:300-6. doi:10.1176/ appi.neuropsych.12100240

16. Foo J, Liu J, Tan E. Whole-genome and whole-exome sequencing in neurological diseases. Nat Rev Neurol (2012) 8:508-17. doi:10.1038/nrneurol. 2012.148

17. Beck J, Pittman A, Adamson G, Campbell T, Kenny J, Houlden H, et al. Validation of next-generation sequencing technologies in genetic diagnosis of dementia. Neurobiol Aging (2014) 35:261-5. doi:10.1016/ j.neurobiolaging.2013.07.017

18. Nicolas G, Wallon D, Charbonnier C, Quenez O, Rousseau S, Richard AC, et al. Screening of dementia genes by whole-exome sequencing in early-onset Alzheimer disease: input and lessons. Eur J Hum Genet (2015) 24:1-7. doi:10.1038/ejhg.2015.173

19. Van Cauwenberghe C, Van Broeckhoven C, Sleegers K. The genetic landscape of Alzheimer disease: clinical implications and perspectives. Genet Med (2015) 18:421-30. doi:10.1038/gim.2015.117

20. Alzheimer's Association. Alzheimer's disease facts and figures. Alzheimers Dement (2015) 11:332-84. doi:10.1016/j.jalz.2015.02.003

21. Loy CT, Schofield PR, Turner AM, Kwok JB. Review: genetics of dementia. Lancet (2014) 383:828-40. doi:10.1016/S0140-6736(13)60630-3

22. Rhinn H, Fujita R, Qiang L, Cheng R, Lee JH, Abeliovich A. Integrative genomics identifies APOE $\varepsilon 4$ effectors in Alzheimer's disease. Nature (2013) 500:45-50. doi:10.1038/nature12415

23. Leoni V. The effect of apolipoprotein $\mathrm{E}$ (ApoE) genotype on biomarkers of amyloidogenesis, tau pathology and neurodegeneration in Alzheimer's disease. Clin Chem Lab Med (2011) 49:375-83. doi:10.1515/CCLM. 2011.088

24. Farrer LA, Cupples LA, Haines JL, Hyman B, Kukull WA, Mayeux R, et al. Effects of age, sex, and ethnicity on the association between apolipoprotein E genotype and Alzheimer disease. JAMA (1997) 278:1349-56. doi:10.1001/ jama.1997.03550160069041 
25. Liu C, Kanekiyo T, Xu H, Bu G. Apolipoprotein E and Alzheimer disease: risk, mechanisms and therapy. Nat Rev Neurol (2013) 9:106-18. doi:10.1038/ nrneurol.2013.32

26. Saunders AM, Hulette C, Welsh-Bohmer KA, Schmechel DE, Crain B, Burke JR, et al. Specificity, sensitivity, and predictive value of apolipoprotein-E genotyping for sporadic Alzheimer's disease. Lancet (1996) 348:90-3. doi:10.1016/S0140-6736(96)01251-2

27. Elias-Sonnenschein LS, Viechtbauer W, Ramakers IH, Verhey FR, Visser PJ. Predictive value of APOE- $\varepsilon 4$ allele for progression from MCI to AD-type dementia: a meta-analysis. J Neurol Neurosurg Psychiatry (2011) 82:1149-56. doi:10.1136/jnnp.2010.231555

28. Vos SJ, Van Rossum IA, Verhey F, Knol DL, Soininen H, Wahlund LO, et al. Prediction of Alzheimer disease in subjects with amnestic and nonamnestic MCI. Neurology (2013) 80:1-9. doi:10.1212/WNL.0b013e318288690c

29. Vos SJ, Xiong C, Visser PJ, Jasielec MS, Hassenstab J, Grant EA, et al. Preclinical Alzheimer's disease and its outcome: a longitudinal cohort study. Lancet Neurol (2013) 12:957-65. doi:10.1016/S1474-4422(13)70194-7

30. Corder E, Saunders A, Strittmatter D, Schmechel D, Gaskell P, Small G, et al. Gene dose of apolipoprotein E type 4 allele and the risk of Alzheimer's disease on late onset families. Science (1993) 261:921-3. doi:10.1126/science.8346443

31. Gupta VB. Plasma apolipoprotein E and Alzheimer disease risk. Neurology (2011) 76:1091-8. doi:10.1212/WNL.0b013e318211c352

32. Lambert JC, Ibrahim-Verbaas CA, Harold D, Naj AC, Sims R, Bellenguez C, et al. Meta-analysis of 74,046 individuals identifies 11 new susceptibility loci for Alzheimer's disease. Nat Genet (2013) 45:1452-8. doi:10.1038/ng.2802

33. Chapuis J, Hansmannel F, Gistelinck M, Mounier A, Van Cauwenberghe C, Kolen KV, et al. Increased expression of BIN1 mediates Alzheimer genetic risk by modulating tau pathology. Mol Psychiatry (2013) 18:1225-34. doi:10.1038/mp.2013.1

34. Tan MS, Yu JT, Tan L. Bridging integrator 1 (BIN1): form, function, and Alzheimer's disease. Trends Mol Med (2013) 19:594-603. doi:10.1016/ j.molmed.2013.06.004

35. Calafate S, Flavin W, Verstreken P, Moechars D. Loss of Bin 1 promotes the propagation of Tau pathology. Cell Rep (2016) 17:931-40. doi:10.1016/ j.celrep.2016.09.063

36. Sottejeau Y, Bretteville A, Cantrelle FX, Malmanche N, Demiaute F, Mendes $\mathrm{T}$, et al. Tau phosphorylation regulates the interaction between BIN1's SH3 domain and Tau's proline-rich domain. Acta Neuropathol Commun (2015) 3:58. doi:10.1186/s40478-015-0237-8

37. Belbin O, Carrasquillo MM, Crump M, Culley OJ, Hunter TA, Ma L, et al. Investigation of 15 of the top candidate genes for late-onset Alzheimer's disease. Hum Genet (2011) 129:273-82. doi:10.1007/s00439-010-0924-2

38. Seshadri S, Fitzpatrick A, Ikram M, DeStefano A, Gudnason V, Boada M, et al. Genome-wide analysis of genetic loci. JAMA (2010) 303:1832-40. doi:10.1001/jama.2010.574

39. Thomas RS, Henson A, Gerrish A, Jones L, Williams J, Kidd EJ. Decreasing the expression of PICALM reduces endocytosis and the activity of $\beta$-secretase: implications for Alzheimer's disease. BMC Neurosci (2016) 17:50. doi:10.1186/s12868-016-0288-1

40. Li X, Ma Y, Wei X, Li Y, Wu H, Zhuang J, et al. Clusterin in Alzheimer's disease: a player in the biological behavior of amyloid-beta. Neurosci Bull (2014) 30:162-8. doi:10.1007/s12264-013-1391-2

41. Desikan RS, Thompson WK, Holland D, Hess CP, Brewer JB, Zetterberg H, et al. The role of clusterin in amyloid-beta-associated neurodegeneration. JAMA Neurol (2014) 71:180-7. doi:10.1001/jamaneurol.2013.4560

42. Thambisetty M, Simmons A, Velayudhan L, Hye A, Campbell J, Zhang Y, et al. Association of plasma clusterin concentration with severity, pathology, and progression in alzheimer disease. Arch Gen Psychiatry (2010) 67:739-48. doi:10.1001/archgenpsychiatry.2010.78

43. Yu JT, Tan L. The role of clusterin in Alzheimer's disease: pathways, pathogenesis, and therapy. Mol Neurobiol (2012) 45:314-26. doi:10.1007/ s12035-012-8237-1

44. Weinstein G, Beiser AS, Preis SR, Courchesne P, Chouraki V, Levy D, et al. Blood-based biomarkers plasma clusterin levels and risk of dementia, Alzheimer's disease, and stroke. Alzheimers Dement (2016) 3:103-9. doi:10.1016/j.dadm.2016.06.005

45. Jonsson T, Stefansson H, Steinberg S, Jonsdottir I, Jonsson PV, Snaedal J, et al. Variant of TREM2 associated with the risk of Alzheimer's disease. N Engl J Med (2013) 368:107-16. doi:10.1056/NEJMoa1211103
46. Jin SC, Carrasquillo MM, Benitez BA, Skorupa T, Carrell D, Patel D, et al. TREM2 is associated with increased risk for Alzheimer's disease in African Americans. Mol Neurodegener (2015) 10:19. doi:10.1186/s13024-0150016-9

47. Colonna M, Wang Y. TREM2 variants: new keys to decipher Alzheimer disease pathogenesis. Nat Rev Neurosci (2016) 17:201-7. doi:10.1038/ nrn.2016.7

48. Takahashi K, Prinz M, Stagi M, Chechneva O, Neumann H. TREM2transduced myeloid precursors mediate nervous tissue debris clearance and facilitate recovery in an animal model of multiple sclerosis. PLoS Med (2007) 4:e124. doi:10.1371/journal.pmed.0040124

49. International Multiple Sclerosis Genetics Consortium; Wellcome Trust Case Control Consortium 2, Sawcer S, Hellenthal G, Pirinen M, Spencer CC, Patsopoulos NA, et al. Genetic risk and a primary role for cell-mediated immune mechanisms in multiple sclerosis. Nature (2011) 476:214-9. doi:10.1038/nature10251

50. Yu L, Chibnik LB, Srivastava GP, Pochet N, Yang J, Xu J, et al. Association of brain DNA methylation in SORL1, ABCA7, HLA-DRB5, SLC24A4, and BIN1 with pathological diagnosis of Alzheimer disease. JAMA Neurol (2015) 72:15-24. doi:10.1001/jamaneurol.2014.3049

51. Adams HH, de Bruijn RFAG, Hofman A, Uitterlinden AG, van Duijn CM, Vernooij MW, et al. Genetic risk of neurodegenerative diseases is associated with mild cognitive impairment and conversion to dementia. Alzheimers Dement (2015) 11:1277-85. doi:10.1016/j.jalz.2014.12.008

52. Sleegers K, Bettens K, De Roeck A, Van Cauwenberghe C, Cuyvers E, Verheijen J, et al. A 22-single nucleotide polymorphism Alzheimer risk score correlates with family history, onset age, and cerebrospinal fluid abeta. Alzheimers Dement (2015) 11:1452-60. doi:10.1016/j.jalz.2015. 02.013

53. Morgen K, Ramirez A, Frölich L, Tost H, Plichta MM, Kölsch H, et al. Genetic interaction of PICALM and APOE is associated with brain atrophy and cognitive impairment in Alzheimer's disease. Alzheimers Dement (2014) 10:1-8. doi:10.1016/j.jalz.2013.11.001

54. Tapiola T, Alafuzoff I, Herukka S, Parkkinen L, Soininen H, Hartikainen P, et al. Cerebrospinal fluid beta-amyloid 42 and tau proteins as biomarkers of Alzheimer-type pathologic changes in the brain. Arch Neurol (2009) 66:382-9. doi:10.1001/archneurol.2008.596

55. Bateman RJ, Munsell LY, Morris JC, Swarm R, Yarasheski KE, Holtzman DM. Human amyloid-beta synthesis and clearance rates as measured in cerebrospinal fluid in vivo. Nat Med (2006) 12:856-61. doi:10.1038/nm1438

56. Taylor JP, Hardy J, Fischbeck KH. Toxic proteins in neurodegenerative disease. Science (2002) 296:1991-5. doi:10.1126/science.1067122

57. Kapaki E, Paraskevas GP, Zalonis I, Zournas C. CSF tau protein and beta-amyloid (1-42) in Alzheimer's disease diagnosis: discrimination from normal ageing and other dementias in the Greek population. Eur J Neurol (2003) 10:119-28. doi:10.1046/j.1468-1331.2003.00562.x

58. De Jong D, Jansen RW, Kremer BPH, Verbeek MM. Cerebrospinal fluid amyloid beta42/phosphorylated tau ratio discriminates between Alzheimer's disease and vascular dementia. J Gerontol A Biol Sci Med Sci (2006) 61:755-8. doi:10.1093/gerona/61.7.755

59. Mulder C, Verwey NA, van der Flier WM, Bouwman FH, Kok A, van Elk EJ, et al. Amyloid-beta(1-42), total tau, and phosphorylated tau as cerebrospinal fluid biomarkers for the diagnosis of Alzheimer disease. Clin Chem (2010) 56:248-53. doi:10.1373/clinchem.2009.130518

60. Shaw LM, Vanderstichele H, Knapik-Czajka M, Clark CM, Aisen PS, Petersen $\mathrm{RC}$, et al. Cerebrospinal fluid biomarker signature in Alzheimer's disease neuroimaging initiative subjects. Ann Neurol (2009) 65:403-13. doi:10.1002/ ana. 21610

61. Schneider P, Hampel H, Buerger K. Biological marker candidates of Alzheimer's disease in blood, plasma, and serum. CNS Neurosci Ther (2009) 15:358-74. doi:10.1111/j.1755-5949.2009.00104.x

62. Gravina SA, Ho L, Eckman CB, Long KE, Otvos L, Younkin LH, et al. Amyloid beta protein (ABeta) in Alzheimer's disease brain: biochemical and immunocytochemical analysis with antibodies specific for forms ending at ABeta40 or ABeta42(43). J Biol Chem (1995) 270:7013-6. doi:10.1074/ jbc. 270.13 .7013

63. Gao CM, Yam AY, Wang X, Magdangal E, Salisbury C, Peretz D, et al. A $\beta 40$ oligomers identified as a potential biomarker for the diagnosis of Alzheimer's disease. PLoS One (2010) 5:e15725. doi:10.1371/journal.pone.0015725 
64. Dumurgier J, Schraen S, Gabelle A, Vercruysse O, Bombois S, Laplanche JL, et al. Cerebrospinal fluid amyloid- $\beta 42 / 40$ ratio in clinical setting of memory centers: a multicentric study. Alzheimers Res Ther (2015) 7:30. doi:10.1186/ s13195-015-0114-5

65. Karch CM, Jeng AT, Goate AM. Extracellular tau levels are influenced by variability in tau that is associated with tauopathies. J Biol Chem (2012) 287:42751-62. doi:10.1074/jbc.M112.380642

66. Lewczuk P, Kamrowski-Kruck H, Peters O, Heuser I, Jessen F, Popp J, et al. Soluble amyloid precursor proteins in the cerebrospinal fluid as novel potential biomarkers of Alzheimer's disease: a multicenter study. Mol Psychiatry (2010) 15:138-45. doi:10.1038/mp.2008.84

67. Lloret A, Badia MC, Giraldo E, Ermak G, Alonso MD, Pallardó FV, et al. Amyloid- $\beta$ toxicity and tau hyperphosphorylation are linked via RCAN1 in Alzheimer's disease. J Alzheimers Dis (2011) 27:701-9. doi:10.3233/ JAD-2011-110890

68. Braunewell KH, Szanto AJK. Visinin-like proteins (VSNLs): interaction partners and emerging functions in signal transduction of a subfamily of neuronal Ca2+-sensor proteins. Cell Tissue Res (2009) 335:301-16. doi:10.1007/s00441-008-0716-3

69. Schnurra I, Bernstein HG, Riederer P, Braunewell KH. The neuronal calcium sensor protein VILIP-1 is associated with amyloid plaques and extracellular tangles in Alzheimer's disease and promotes cell death and tau phosphorylation in vitro: a link between calcium sensors and Alzheimer's disease? Neurobiol Dis (2001) 8:900-9. doi:10.1006/nbdi.2001.0432

70. Laterza O, Modur V, Crimmins DL, Olander J, Landt Y, Lee J, et al. Identification of novel brain biomarkers. Clin Chem (2006) 52:1713-21. doi:10.1373/clinchem.2006.070912

71. Tarawneh R, D’Angelo G, MacY E, Xiong C, Carter D, Cairns NJ, et al. Visinin-like protein-1: diagnostic and prognostic biomarker in Alzheimer disease. Ann Neurol (2011) 70:274-85. doi:10.1002/ana.22448

72. Tzen KY, Yang SY, Chen TF, Cheng TW, Horng HE, Wen HP, et al. Plasma A $\beta$ but not tau is related to brain PiB retention in early Alzheimer's disease. ACS Chem Neurosci (2014) 5:830-6. doi:10.1021/cn500101j

73. Vlassenko AG, Benzinger TLS, Morris JC. PET amyloid-beta imaging in preclinical Alzheimer's disease. Biochim Biophys Acta (2012) 1822:370-9. doi:10.1016/j.bbadis.2011.11.005

74. Rosén C, Hansson O, Blennow K, Zetterberg H. Fluid biomarkers in Alzheimer's disease - current concepts. Mol Neurodegener (2013) 8:20. doi:10.1186/1750-1326-8-20

75. Craig-Schapiro R, Perrin RJ, Roe CM, Xiong C, Carter D, Cairns NJ, et al. YKL-40: a novel prognostic fluid biomarker for preclinical Alzheimer's disease. Biol Psychiatry (2010) 68:903-12. doi:10.1016/j.biopsych.2010.08.025

76. Johansen JS, Jensen BV, Roslind A, Nielsen D, Price PA. Serum YKL-40, a new prognostic biomarker in cancer patients? Cancer Epidemiol Biomarkers Prev (2006) 15:194-202. doi:10.1158/1055-9965.EPI-05-0011

77. Wennström M, Surova Y, Hall S, Nilsson C, Minthon L, Hansson O, et al. The inflammatory marker YKL-40 is elevated in cerebrospinal fluid from patients with Alzheimer's but not Parkinson's disease or dementia with Lewy bodies. PLoS One (2015) 10:e0135458. doi:10.1371/journal.pone.0135458

78. Hellwig K, Kvartsberg H, Portelius E, Andreasson U, Oberstein TJ, Lewczuk P, et al. Neurogranin and YKL-40: independent markers of synaptic degeneration and neuroinflammation in Alzheimer's disease. Alzheimers Res Ther (2015) 7:74. doi:10.1186/s13195-015-0161-y

79. Janelidze S, Hertze J, Zetterberg H, Landqvist Waldo M, Santillo A, Blennow $\mathrm{K}$, et al. Cerebrospinal fluid neurogranin and YKL-40 as biomarkers of Alzheimer's disease. Ann Clin Transl Neurol (2015) 3:12-20. doi:10.1002/ acn 3.266

80. Chang JW, Schumacher E, Coulter PM II, Vinters HV, Watson JB. Dendritic translocation of RC3/neurogranin mRNA in normal aging, Alzheimer disease and fronto-temporal dementia. J Neuropathol Exp Neurol (1997) 56:1105-18. doi:10.1097/00005072-199710000-00004

81. Kester MI, Teunissen CE, Crimmins DL, Herries EM, Ladenson JH, Scheltens $\mathrm{P}$, et al. Neurogranin as a cerebrospinal fluid biomarker for synaptic loss in symptomatic Alzheimer disease. JAMA Neurol (2015) 72:1275-80. doi:10.1001/jamaneurol.2015.1867

82. De Vos A, Struyfs H, Jacobs D, Fransen E, Klewansky T, De Roeck E, et al. The cerebrospinal fluid neurogranin/BACE1 ratio is a potential correlate of cognitive decline in Alzheimer's disease. J Alzheimers Dis (2016) 53:1523-38. doi:10.3233/JAD-160227
83. Vassar R. BACE1 inhibitor drugs in clinical trials for Alzheimer's disease. Alzheimers Res Ther (2014) 6:89. doi:10.1186/s13195-014-0089-7

84. Demarin V, Zavoreo I, Kes VB, Šimundić AM. Biomarkers in Alzheimer's disease. Clin Chem Lab Med (2011) 49:773-8. doi:10.1515/CCLM.2011.139

85. Björkqvist M, Ohlsson M, Minthon L, Hansson O. Evaluation of a previously suggested plasma biomarker panel to identify Alzheimer's disease. PLoS One (2012) 7:e29868. doi:10.1371/journal.pone.0029868

86. Ray S, Britschgi M, Herbert C, Takeda-Uchimura Y, Boxer A, Blennow K, et al. Classification and prediction of clinical Alzheimer's diagnosis based on plasma signaling proteins. Nat Med (2007) 13:1359-62. doi:10.1038/ nm1653

87. Hye A, Riddoch-Contreras J, Baird AL, Ashton NJ, Bazenet C, Leung R, et al. Plasma proteins predict conversion to dementia from prodromal disease. Alzheimers Dement (2014) 10:799-807. doi:10.1016/j.jalz.2014.05.1749

88. Kiddle SJ, Sattlecker M, Proitsi P, Simmons A, Westman E, Bazenet C, et al. Candidate blood proteome markers of Alzheimer's disease onset and progression: a systematic review and replication study. J Alzheimers Dis (2014) 38:515-31. doi:10.3233/JAD-130380

89. Mapstone M, Cheema AK, Fiandaca MS, Zhong X, Mhyre TR, MacArthur $\mathrm{LH}$, et al. Plasma phospholipids identify antecedent memory impairment in older adults. Nat Med (2014) 20:415-8. doi:10.1038/nm.3466

90. Leidinger P, Backes C, Deutscher S, Schmitt K, Mueller SC, Frese K, et al. A blood based 12-miRNA signature of Alzheimer disease patients. Genome Biol (2013) 14:R78. doi:10.1186/gb-2013-14-7-r78

91. Bhatnagar S, Chertkow H, Schipper HM, Yuan Z, Shetty V, Jenkins S, et al. Increased microRNA-34c abundance in Alzheimer's disease circulating blood plasma. Front Mol Neurosci (2014) 7:2. doi:10.3389/fnmol.2014.00002

92. Cheng L, Doecke JD, Sharples RA, Villemagne VL, Fowler CJ, Rembach A, et al. Prognostic serum miRNA biomarkers associated with Alzheimer's disease shows concordance with neuropsychological and neuroimaging assessment. Mol Psychiatry (2014) 20:1-9. doi:10.1038/mp.2014.127

93. Hye A, Lynham S, Thambisetty M, Causevic M, Campbell J, Byers HL, et al. Proteome-based plasma biomarkers for Alzheimer's disease. Brain (2006) 129:3042-50. doi:10.1093/brain/awl279

94. Cogswell JP, Ward J, Taylor IA, Waters M, Shi Y, Cannon B, et al. Identification of miRNA changes in Alzheimer's disease brain and CSF yields putative biomarkers and insights into disease pathways. J Alzheimers Dis (2008) 14:27-41. doi:10.1016/j.jalz.2008.05.420

95. Geekiyanage H, Jicha GA, Nelson PT, Chan C. Blood serum miRNA: non-invasive biomarkers for Alzheimer's disease. Exp Neurol (2012) 235:491-6. doi:10.1016/j.expneurol.2011.11.026

96. Chim CS, Wan TS, Wong KY, Fung TK, Drexler HG, Wong KF. Methylation of miR-34a, miR-34b/c, miR-124-1 and miR-203 in Ph-negative myeloproliferative neoplasms. J Transl Med (2011) 9:197-207. doi:10.1186/14795876-9-197

97. Li XJ, Ren ZJ, Tang JH. MicroRNA-34a: a potential therapeutic target in human cancer. Cell Death Dis (2014) 5:e1327. doi:10.1038/cddis.2014.270

98. Villemagne VL, Burnham S, Bourgeat P, Brown B, Ellis KA, Salvado O, et al. Amyloid $\beta$ deposition, neurodegeneration, and cognitive decline in sporadic Alzheimer's disease: a prospective cohort study. Lancet Neurol (2013) 12:357-67. doi:10.1016/S1474-4422(13)70044-9

99. van Oijen M, Hofman A, Soares HD, Koudstaal PJ, Breteler MM. Plasma $\mathrm{A} \beta 1-40$ and $\mathrm{A} \beta 1-42$ and the risk of dementia: a prospective case-cohort study. Lancet Neurol (2006) 5:655-60. doi:10.1016/S1474-4422(06) 70501-4

100. Chouraki V, Beiser A, Younkin L, Preis SR, Weinstein G, Hansson O, et al. Plasma amyloid- $\beta$ and risk of Alzheimer's disease in the Framingham Heart Study. Alzheimers Dement (2015) 11:249-57. doi:10.1016/j.jalz.2014. 07.001

101. Lui J, Laws S, Li Q, Villemagne V, Ames D, Brown B, et al. Plasma amyloid-beta as a biomarker in Alzheimer's disease: the AIBL study of aging. J Alzheimers Dis (2010) 20:1233-42. doi:10.3233/JAD-2010-090249

102. Rembach A, Faux NG, Watt AD, Pertile KK, Rumble RL, Trounson BO, et al. Changes in plasma amyloid beta in a longitudinal study of aging and Alzheimer's disease. Alzheimers Dement (2014) 10:53-61. doi:10.1016/j. jalz.2012.12.006

103. Fei M, Jianghua W, Rujuan M, Wei Z, Qian W. The relationship of plasma Abeta levels to dementia in aging individuals with mild cognitive impairment. J Neurol Sci (2011) 305:92-6. doi:10.1016/j.jns.2011.03.005 
104. Ashton NJ, Kiddle SJ, Graf J, Ward M, Baird AL, Hye A, et al. Blood protein predictors of brain amyloid for enrichment in clinical trials? Alzheimer's Dement (2015) 1:48-60. doi:10.1016/j.dadm.2014.11.005

105. Burnham SC, Faux NG, Wilson W, Laws SM, Ames D, Bedo J, et al. A blood-based predictor for neocortical A $\beta$ burden in Alzheimer's disease: results from the AIBL study. Mol Psychiatry (2014) 19:519-26. doi:10.1038/ mp. 2013.40

106. Sperling RA, Rentz DM, Johnson KA, Karlawish J, Donohue M, Salmon DP, et al. The A4 study: stopping AD before symptoms begin? Sci Transl Med (2014) 6:228fs13. doi:10.1126/scitranslmed.3007941

107. Villemagne VL, Pike KE, Chételat G, Ellis KA, Mulligan RS, Bourgeat P, et al. Longitudinal assessment of $A \beta$ and cognition in aging and Alzheimer disease. Ann Neurol (2011) 69:181-92. doi:10.1002/ana.22248

108. Voyle N, Kim M, Proitsi P, Ashton NJ, Baird AL, Bazenet C, et al. Blood metabolite markers of neocortical amyloid- $\beta$ burden: discovery and enrichment using candidate proteins. Transl Psychiatry (2016) 6:e719. doi:10.1038/ tp. 2015.205

109. Chetelat G, La Joie R, Villain N, Perrotin A, De La Sayette V, Eustache F, et al. Amyloid imaging in cognitively normal individuals, at-risk populations and preclinical Alzheimer's disease. Neuroimage Clin (2013) 2:356-65. doi:10.1016/j.nicl.2013.02.006

110. Tarawneh R, Lee JM, Ladenson JH, Morris JC, Holtzman DM. CSF VILIP-1 predicts rates of cognitive decline in early Alzheimer disease. Neurology (2012) 78:709-19. doi:10.1212/WNL.0b013e318248e568

111. Galvin JE, Powlishta KK, Wilkins K, McKeel DW, Xiong C, Grant E, et al. Predictors of preclinical Alzheimer disease and dementia: a clinicopathologic study. Arch Neurol (2005) 62:758-65. doi:10.1001/archneur.62.5.758

112. Morris JC. Clinical dementia rating: a reliable and valid diagnostic and staging measure for dementia of the Alzheimer type. Int Psychogeriatr (1997) 9(Suppl 1):173-8. doi:10.1017/S1041610297004870

113. Fagan AM, Xiong C, Jasielec MS, Bateman RJ, Goate AM, Benzinger TLS, et al. Longitudinal change in CSF biomarkers in autosomal-dominant Alzheimer's disease. Sci Transl Med (2014) 6:226ra30. doi:10.1126/scitranslmed.3007901

114. Rodríguez-Rodríguez E, Sánchez-Juan P, Vázquez-Higuera JL, Mateo I, Pozueta A, Berciano J, et al. Genetic risk score predicting accelerated progression from mild cognitive impairment to Alzheimer's disease. J Neural Transm (2013) 120:807-12. doi:10.1007/s00702-012-0920-x
115. Blennow K, Zetterberg H, Rinne JO, Salloway S, Wei J, Black R, et al. Effect of immunotherapy with bapineuzumab on cerebrospinal fluid biomarker levels in patients with mild to moderate Alzheimer disease. Arch Neurol (2012) 69:1002-10. doi:10.1001/archneurol.2012.90

116. Rinne JO, Brooks DJ, Rossor MN, Fox NC, Bullock R, Klunk WE, et al. 11C$\mathrm{PiB}$ PET assessment of change in fibrillar amyloid- $\beta$ load in patients with Alzheimer's disease treated with bapineuzumab: a phase 2, double-blind, placebo-controlled, ascending-dose study. Lancet Neurol (2010) 9:363-72. doi:10.1016/S1474-4422(10)70043-0

117. Mattsson N, Carrillo MC, Dean RA, Devous MD Sr, Nikolcheva T, Pesini $\mathrm{P}$, et al. Revolutionizing Alzheimer's disease and clinical trials through biomarkers. Alzheimers Dement (2015) 1:1-8. doi:10.1016/j.dadm.2015. 09.001

118. Ritter A, Cummings J. Fluid biomarkers in clinical trials of Alzheimer's disease therapeutics. Front Neurol (2015) 6:186. doi:10.3389/fneur.2015. 00186

119. Schneider LS, Mangialasche F, Andreasen N, Feldman H, Giacobini E, Jones $\mathrm{R}$, et al. Clinical trials and late-stage drug development for Alzheimer's disease: an appraisal from 1984 to 2014. J Intern Med (2014) 275:251-83. doi:10.1111/joim.12191

120. Doody RS, Thomas RG, Farlow M, Iwatsubo T, Vellas B, Joffe S, et al. Phase 3 trials of solanezumab for mild-to-moderate Alzheimer's disease. $N$ Engl J Med (2014) 370:311-21. doi:10.1056/NEJMoa1312889

121. Salloway S, Sperling R, Fox NC, Blennow K, Klunk W, Raskind M, et al. Two phase 3 trials of bapineuzumab in mild-to-moderate Alzheimer's disease. $N$ Engl J Med (2014) 370:322-33. doi:10.1056/NEJMoa1304839

Conflict of Interest Statement: The authors declare that the research was conducted in the absence of any commercial or financial relationships that could be construed as a potential conflict of interest.

Copyright (C) 2017 Huynh and Mohan. This is an open-access article distributed under the terms of the Creative Commons Attribution License (CC BY). The use, distribution or reproduction in other forums is permitted, provided the original author(s) or licensor are credited and that the original publication in this journal is cited, in accordance with accepted academic practice. No use, distribution or reproduction is permitted which does not comply with these terms. 